\title{
Friction and wear behaviour of dual phase steels in discontinuous sliding contact conditions as a function of sliding speed and contact frequency
}

\author{
M. Ruiz-Andres, A. Conde, J. de Damborenea, I. Garcia* \\ Department of Surface Engineering, Corrosion and Durability, National Center for \\ Metallurgical Research (CENIM-CSIC), Avda. Gregorio del Amo 8, 28040, Madrid, \\ Spain \\ *E-mail address: igarcia@ cenim.csic.es
}

\begin{abstract}
Friction and wear rate behaviour of dual phase steel discs (DP600) as a function of sliding speed $(0.05-3.75 \mathrm{~m} / \mathrm{s})$, and contact frequency $(0.6-16.5 \mathrm{~Hz})$ have been studied under unidirectional ball-on-disc dry sliding conditions. The coefficient of friction (COF) and wear rate exhibit not only a highly dependence on the sliding speed, but also on the contact frequency which appears to be the key factor determining the wear behaviour of the DP600 even at constant sliding speed. The wear mechanism is mainly oxidative. The validity of Garcia-Ramil-Celis model is demonstrated for discontinuous sliding contacts at contact frequencies below $7 \mathrm{~Hz}$. However, above $7 \mathrm{~Hz}$, the disc behaves as if it were subjected to a continuous sliding contact.
\end{abstract}

Keywords: Steel, sliding wear, contact frequency, oxidative wear 


\section{Introduction}

Traditionally, normal contact load and sliding speed are considered the most important parameters in tribological systems. These parameters are commonly used to construct contact wear maps, which are a useful tool to predict the conditions under which a tribosystem can operate safely [1].

Wear maps have been experimentally and theoretically constructed for systems based on technological important materials, such as steel sliding versus steel [2], steel versus nitrided steel [3], and also aluminium alloys versus steel [1,4]. In those wear maps, a small variation in contact pressure, and/or in sliding speed, may result in a significant transition between the two distinct wear mechanisms.

Wear mechanism occurred in dry sliding tests have been classified in literature [5-8] into different types. All these classifications are strongly related to the previous classifications proposed by Burwell et al. [5], with seven wear types, and Archard et al. [9], with only two. Tabor [7] just distinguished three types: adhesive, non-adhesive, and a mixture of both. The author discussed the nature of the atomic forces at the interface but also the way the interface deforms under the action of a pull-off force (for adhesion) or a tangential force (for sliding), and how the bond itself ruptures under shearing. Ludema [6] defined scuffing, namely the roughening of surfaces by plastic flow whether or not there is material loss or transfer. Whilst Quinn [8] established mild and severe wear as the two main mechanisms of wear.

Oxidative wear is a form of mild wear, one of the two basic classifications for nonlubricated sliding wear firstly proposed by Archard et al. [9]. While mild wear is characterised by oxidised wear debris generation and smooth oxidised wear surfaces. This type of wear clearly involves a reaction with the environment, in particular with oxygen [10]. Moreover, the oxidative wear mechanism occurs when sliding surfaces are subjected to thermal oxidation. The heat is externally provided with a heat source, or internally by the frictional heat produced in the sliding contact.

The mild oxidative wear model proposed by Quinn [10-14] for a tribosystem comprised by a pin sliding against a disc, takes place in two successive steps. Initially, the asperities on both surfaces the body (pin) and the counterbody (disc) oxidise as a consequence of a high local rise in temperature due to friction. The oxide layers formed 
at these asperities usually grow following a parabolic trend or linear growth law [15]. Then, when locally a critical oxide thickness is reached at the asperities, the oxide layer breaks off and a new oxide layer is generated on the freshly exposed metallic surface. Thus the expression for the volumetric wear loss in a pin, $\mathrm{W}$, leads to as follows:

$W=\frac{d A_{c} \exp \left(-Q / R T_{f}\right)}{\xi^{2} \rho^{2} v} \frac{F}{H} L$

where $d$ is the asperity contact area average diameter, $A_{c}$ the oxidation activity factor, $Q$ the Arrhenius activation energy for oxidation, $R$ the gas constant, $T_{f}$ the local temperature at the asperity, $F$ the normal load, $L$ the sliding distance, $\xi$ the critical oxide thickness, $\rho$ the density for the material tested, $\mathrm{v}$ the sliding speed, and $H$ the hardness for the material tested.

Once the oxide layer is broken off, the oxide particles formed from the layer may agglomerate to generate a protective layer establishing equilibrium between formation and delamination or fragmentation of the layer $[16,17]$. When performing wear tests using a pin/ball-on-disc configuration, the pin itself -or the ball- is under continuous contact with the disc, and consequently, as the contact load and the sliding speed are considered the controlling operational wear parameters which best define the wear test conditions for a wide range of materials, the material of the pin would become fully characterized. However, when the aim is the characterisation of the wear rate or wear mechanism of the disc material the contact varies since the disc and the ball are not equivalent in a pin/ball-on-disc wear tests.

Garcia et al. [18] developed a novel approach to sliding ball-on-disc wear tests considering that, from the viewpoint of the disc, each part of the wear track is in discontinuous contact with the counterbody. The authors found that the contact frequency, defined by the rotation frequency of the disc, became the most influencing parameter on the wear rate of TiN coated steel discs when tested in a pin/ball-on disc configuration. The role of the contact frequency was also later confirmed in ball-on-disc wear tests on tool carbon steel discs sliding against corundum [19]. The need of considering contact frequency on tribocorrosion systems has been also pointed out in recent mathematical models for sliding wear in both gaseous and aqueous environments [20], In nuclear pressurized water reactors (PWR), some tubular components wear 
damage have been found to be also sensitive to the activation or latency time (inverse of the contact frequency) resulting from vibrating contacts [21].

Wear studies are found in almost all industrial sectors due to the relevance of a surface failure, which can negatively alter the performance of industrial facilities, shorten their service life and comprising safety issues [22]. Over the last decades, huge efforts have been made to develop materials of high wear properties to achieve optimal performance with maximised service life.

One of these new materials with improved properties is the microstructure-strengthened steel [23], namely DP steels. The unique combination of mechanical properties such as strength, ductility [24, 25], toughness, good formability and excellent surface finish [26] makes them to one of the most important recent advances in high strength low alloy steels (HSLA).

Dual phase steels are considered as light steels with high strength [27], consisting of about $75-85 \%$ continuous ductile ferrite matrix phase with the remainder being mainly hardened martensite islands randomly distributed [28]. Moreover, they are known for being widely used in the automotive industry due to the need for improving fuel efficiency [29-31], with its subsequent energy saving and environmental protection [32].

Although some researchers [33-43] have worked on the tribological aspects of DP steels, there is still a need to develop a more comprehensive understanding of their friction and wear behaviour, taking into account the specific characteristic of the interaction of these steels in discontinuous sliding contacts.

The present work focuses on the role of the contact frequency as an operational wear parameter in ball-on-disc tests operating under dry sliding conditions. The wear tests were, conducted on high strength DP steel disc materials sliding against corundum balls. The friction behaviour and the wear evolution of these DP steel discs were carefully analysed at specific sliding speeds and rotation frequencies

\section{Experimental}

A commercial high strength low carbon dual phase steel, namely DP600, was used in this work. The chemical composition of this DP600 steel is given in Table 1. The as- 
received material was an industrially processed, cold-rolled sheet with a hardness of 230 $\pm 5 \mathrm{HV}_{1 \mathrm{kgf}}$ and a thickness of $1.5 \mathrm{~mm}$. Subsequently, this sheet was machined into discs with an outer diameter of $120 \mathrm{~mm}$. The average surface roughness of the steel specimen is $0.386 \mu \mathrm{m}\left(\mathrm{R}_{\mathrm{a}}\right)$ approximately. High purity $(99.9 \%)$ corundum balls with $3 \mathrm{~mm}$ of diameter and surface roughness of $12.83 \mathrm{~nm}\left(\mathrm{R}_{\mathrm{a}}\right)$ were selected as counterbody due to its high wear resistance and its chemical inertness.

Tribological characterisation was conducted using a unidirectional ball-on-disc UMT-2Bruker tribometer. In this configuration, the corundum ball was loaded on top of the disc. This set-up facilitates the third body interaction since it limits the ejection of the debris from the contact area in comparison to other configuration where the disc is loaded on top of the pin/ball. Wear tests were carried out at a steady contact load of $2 \mathrm{~N}$ for 2000 total number of cycles. These tests were performed under ambient conditions without lubrication. The room temperature was $25 \pm 2{ }^{\circ} \mathrm{C}$ and the relative humidity of the surrounding atmosphere was $40 \% \mathrm{RH}$ approximately. Previously to wear testing, all the specimens were degreased with suitable solvents and dried by blowing cold air on to them.

In order to independently study the effect of linear sliding speed, and/or rotation -or contact- frequency on the wear rate for the DP600 discs, a thoroughly design of the experimental parameters were used. Notice that the sliding speed (linear speed), $v$, at a given contact frequency (angular speed), $f$, varies by adjusting the wear track diameter, $D$, in the case of pin-on-disc or ball-on-disc sliding tests. These three operational parameters are related to as follows:

$\nu=\pi \cdot f \cdot D$

Whereby, series of ball-on-disc wear tests were conducted at a given constant sliding speed but at different rotation speeds by modifying the wear track diameter to adjust the Eq. (2). In addition, series of ball-on-disc wear tests were carried out at a fixed rotation speed but at different sliding speeds, once again modifying the wear track diameter. In this sense, the sliding speed was varied between 0.1 and $3.75 \mathrm{~m} / \mathrm{s}$ and the track diameter ranged within an interval from 12 to $75 \mathrm{~mm}$. Thus the contact frequency studied in the present work varied between 0.6 and $16 \mathrm{~Hz}$. 
The volume wear loss of the disc was determined by optical confocal profilometer, Sensofar PL $\mu 2300$. The volume wear loss was calculated from the average of the crosssectional area measured at four different locations along the wear track, and multiplied by the wear track length. The wear rate, as a function of the different experimental conditions, was obtained by dividing the volume wear loss per unit load and sliding distance.

Visual examinations -made by optical microscope Olympus Gx51- of the counterbody corundum ball after the wear tests completion show that the wear can be considered negligible (Fig. 1); as expected due to the notably higher hardness of the corundum, approximately $2060 \mathrm{HV}$, in comparison with the steel disc. The amount of debris in the contact area between both bodies -ball and disc- is small and not adherent. However, this small amount of debris could behave also as a solid lubricant and, consequently, diminish and/or even avoid wear in the hardest body of the tribopair.

The worn surfaces were examined by field emission gun scanning electron microscopy (FEG-SEM, Hitachi S-4800) equipped with energy dispersive spectroscopy (EDS) facilities. Moreover, the wear debris were collected and analysed by SEM, EDS and Xray diffraction (XRD). XRD analyses were performed using a $\mathrm{Co}-\mathrm{K} \alpha$ monochromatic radiation, with a wavelength of $\lambda=1.789 \AA$.

\section{Results}

\subsection{Worn surfaces and wear debris}

Fig. 2 (a)-(b) show SEM images of the wear tracks formed on the DP600 disc during the dry sliding wear tests at a contact frequency of $1.20 \mathrm{~Hz}$ and a sliding speed of $0.1 \mathrm{~m} / \mathrm{s}$, and at a contact frequency of $16 \mathrm{~Hz}$ and a sliding speed of $0.9 \mathrm{~m} / \mathrm{s}$, as the representative behaviour of the results obtained at low and high contact frequencies/sliding speeds, respectively. Wear tracks are characterised by surface deformation in form of smooth longitudinal grooves running parallel to the sliding direction. SEM images also reveal that the wear mechanism is mainly oxidative in both cases, although at $16 \mathrm{~Hz}$ and 0.9 $\mathrm{m} / \mathrm{s}$, larger oxidised areas along the wear track are observed.

The EDS spectra of the worn surfaces along the tracks at these two contact frequencies are plotted in Fig. 3 (a), i.e. $1.20 \mathrm{~Hz}$ and $0.1 \mathrm{~m} / \mathrm{s}$, and Fig. 3 (b), i.e. $16 \mathrm{~Hz}$ and $0.9 \mathrm{~m} / \mathrm{s}$. 
Both spectra show the presence of $\mathrm{Fe}, \mathrm{O}$ and $\mathrm{C}$ species, indicating thus that the DP600 worn surfaces have been oxidised during the dry sliding wear process.

Higher magnifications of the scanning electron micrographs, in Fig. 4-5, show the wear debris produced at these contact frequencies and sliding speeds, $1.20 \mathrm{~Hz}$ and $0.1 \mathrm{~m} / \mathrm{s}$, and $16 \mathrm{~Hz}$ and $0.9 \mathrm{~m} / \mathrm{s}$, and their respective EDS spectra. At the lowest contact frequency, Fig. 4 (a)-(b), the wear particles seem to be predominantly comprised by irregular fine particles of equiaxed shape of approximately $0.2-4 \mu \mathrm{m}$, size. The EDS spectrum (Fig. 4 (c)) of this debris consists of Fe, $\mathrm{O}$ and $\mathrm{C}$ species, showing the presence of oxidised compounds.

The debris collected at $16 \mathrm{~Hz}$ and $0.9 \mathrm{~m} / \mathrm{s}$, Fig. 5 (a)-(c), shows a similar appearance, fine equiaxed particles. Nevertheless, the difference in size with regard to the debris collected at low contact frequencies is clearly observed. The size of the debris particles varies from 0.1 to $1 \mu \mathrm{m}$.

EDS analysis corresponding to the fine equiaxed wear debris produced at high contact frequency (i.e.16 Hz) shows similar composition to those produced at low contact frequency (Fig. 5 (d)-(e)). Sliding wear at $16 \mathrm{~Hz}$ and $0.9 \mathrm{~m} / \mathrm{s}$ produces wear oxidised debris, with the presence of $\mathrm{Fe}, \mathrm{O}$ and $\mathrm{C}$ species.

The oxidative wear mechanism involved in these dry sliding wear tests is further confirmed by the XRD diffractograms. Fig. 6 shows the XRD diffractograms of the collected debris generated at low and high contact frequencies, respectively. At $1.20 \mathrm{~Hz}$ (Fig. 6 (a)), the XRD diffractogram reveals two phases, namely hematite $\left(\mathrm{Fe}_{2} \mathrm{O}_{3}\right)$ and alpha-iron $(\alpha-\mathrm{Fe})$, whereas at $16 \mathrm{~Hz}$ XRD analysis determines that the main wear debris constituents are magnetite $\left(\mathrm{Fe}_{3} \mathrm{O}_{4}\right)$ and $\alpha$-Fe, (Fig. 6 (b)).

The nature of the iron oxide formed at both low and high contact frequencies can be explained according to the basis of the sliding temperature. Several authors [11,44], based on the static oxidation experiments, reported that the type of oxidised wear debris retrieved from dry sliding wear tests on low alloy steels were directly related to the temperature. According to the authors, for experiments conducted without external heating, the predominant oxide at temperatures below $450{ }^{\circ} \mathrm{C}$ is $\mathrm{Fe}_{2} \mathrm{O}_{3}$; at temperatures ranging from $450^{\circ} \mathrm{C}$ to $600{ }^{\circ} \mathrm{C}$, it is $\mathrm{Fe}_{3} \mathrm{O}_{4}$; whereas, at temperatures greater than $600^{\circ} \mathrm{C}$, $\mathrm{FeO}$ is the predominant oxide in the debris. 
A theoretical estimation of the flash temperature, $T_{f}$, for the different sliding speeds studied (Fig. 7) has been calculated according to the equation given by Lim and Ashby [2], defined as:

$T_{f}=T_{b}\left[1-\left(\frac{\tilde{F}}{N}\right)^{1 / 2}\right]+T_{o}\left(\frac{\tilde{F}}{N}\right)^{1 / 2}+\frac{\mu T_{C}^{*} \beta}{2}\left(\frac{\tilde{F}}{N}\right)^{1 / 2} \tilde{v}$

where $\tilde{F}$ and $\tilde{v}$ stand for normalised load and sliding speed, respectively; $T_{C}^{*}$ is the effective equivalent temperature for metal (650 K approximately, based on calculations made in Appendix 4 [2]), $\beta$ the dimensionless parameter for bulk heating (general order of 1), $\mu$ the coefficient of friction and $N$ is the total number of contacting asperities. Here, $T_{b}$ denotes the bulk temperature which, in turn, is obtained by the following expression:

$T_{b}=T_{o}+\frac{\mu T^{*} \beta}{2+\beta(\pi \tilde{v} / 8)^{1 / 2}} \tilde{F} \tilde{v}$

where $T_{o}$ is the sink temperature for bulk heating (in the present case, $298 \mathrm{~K}$ ).

According to Lim and Ashby [2], the normalised load on the sliding interface, $\tilde{F}$, and the normalised sliding speed, $\widetilde{v}$, are defined in terms of:

$\tilde{F}=\frac{F}{A_{n} H_{O}}$

$\tilde{v}=\frac{v r_{o}}{a}$

In these formulations $F$ is the normal load at the interface, $A_{n}$ the nominal area of contact $\left(7.1 \cdot 10^{-6} \mathrm{~m}^{2}\right.$, approximately), $H_{o}$ the hardness value of the dual phase steel, $v$ the sliding speed, $r_{o}$ the radius of the ball $(1.5 \mathrm{~mm})$ and $a$ is the thermal diffusivity of the metal (about $1.09 \cdot 10^{-5} \mathrm{~m}^{2} / \mathrm{s}$ ).

Requiring, in addition, that $\mathrm{N}$ is expressed as:

$N=\left(\frac{r_{o}}{r_{a}}\right)^{2} \tilde{F}(1-\tilde{F})+1$

where $r_{a}$ the radius of an asperity (with a value about $10^{-5} \mathrm{~m}[2]$ ).

The flash temperatures obtained at low contact frequencies (e.g. $1.20 \mathrm{~Hz} / 0.1 \mathrm{~m} / \mathrm{s}$ ), and high contact frequencies (e.g. $16 \mathrm{~Hz} / 0.9 \mathrm{~m} / \mathrm{s}$ )) are thus in agreement with those 
described in literature $[11,44]$, i.e. below $450^{\circ} \mathrm{C}$, and between $450^{\circ} \mathrm{C}$ and $600^{\circ} \mathrm{C}$, respectively. And the range of the temperatures obtained for the experimental conditions are, therefore, also in agreement with the type of oxides present in the wear debris.

\subsection{Effect of contact frequency and sliding speed on coefficient of friction}

The influence of the rotation speed on the wear behaviour of the DP600 steel disc was studied by performing wear tests at several sliding speeds keeping constant the contact frequency by the adjustment of adequate wear track diameters. The influence was then determined by calculating the wear rate of the dual-phase steel discs and the dynamic $\mathrm{COF}$.

Two distinct wear stages can be easily distinguished in all the COF curves examined. Initially, a very short (less than $5 \%$ of the total sliding time) and steep running-in stage is observed, where the COF rapidly increases up to reach a constant value. This second stage where the COF hardly varies corresponds to steady state stage (Fig. 8). The results presented in the following discussion are representative of the steady state stage, thus the effect of the running-in on the wear rate has not been taken into account.

The dependence of the COF as a function of the contact frequency performed at six fixed sliding speeds, between 0.1 and $2 \mathrm{~m} / \mathrm{s}$, is presented in Fig. 9. It can be noticed that the COF decreases as the contact frequency increases for each given constant sliding speed, e.g. a noticeable change occurs at $0.6 \mathrm{~m} / \mathrm{s}$, where the COF values vary from 0.61 to 0.51 .

On the other hand, an overview of the COF behaviour as a function of the sliding speed, at nine fixed contact frequencies, between 1 and $16 \mathrm{~Hz}$, is given in Fig. 10. A clear correlation of the COF with the sliding speed can be detected. Initially, comparing the data sets for the fixed contact frequencies from 1 to $7 \mathrm{~Hz}$, a steep increase in the COF concurrently with the sliding speed takes place. The COF values significantly vary between 0.4 and 0.62 . Whilst from the fixed contact frequency of $7 \mathrm{~Hz}$ onwards, a distinct dependence emerges. In this case, the COF slightly decreases with the sliding speed. Moreover, even for data obtained at each given constant contact frequency, a strong dependence on the COF with the sliding speed is observed. The lower the fixed contact frequency, the higher the variation in the COF with the sliding speed is 
exhibited. For instance, at $1 \mathrm{~Hz}$, the COF values range from 0.40 to 0.54 , or also at 2 $\mathrm{Hz}$, where the COF values vary between 0.50 and 0.60 . Conversely, the higher the steady contact frequency, the lower the variations in the COF with the sliding speed.

\subsection{Effect of contact frequency and sliding speed on wear rate}

In an attempt to clarify the possible combined role of contact frequency and sliding speed on the DP600 steel, the wear rate of the discs tested at six fixed sliding speeds is presented in Fig. 11, and at nine steady contact frequencies in Fig. 12.

Fig. 11 shows that relationship between the wear rate and the contact frequency for each data set obtained at a fixed sliding speed is inversely proportional. The decrease in wear rate is less abrupt as the given sliding speed grows. Wear rate ranges from $7.2 \cdot 10^{-4}$ to $4.11 \cdot 10^{-4} \mathrm{~mm}^{3} / \mathrm{N} \cdot \mathrm{m}$ at $0.1 \mathrm{~m} / \mathrm{s}$, and from $10.55 \cdot 10^{-4}$ to $5.99 \cdot 10^{-4} \mathrm{~mm}^{3} / \mathrm{N} \cdot \mathrm{m}$ at $2 \mathrm{~m} / \mathrm{s}$.

Conversely, the dependence of the wear rate on the sliding speed at nine fixed contact frequencies, Fig. 12, shows a more complex behaviour. Initially, for fixed contact frequencies comprised from 1 to $7 \mathrm{~Hz}$, the wear rate shows a strong dependence with the sliding speed. The wear rate exhibits an abrupt increase with the sliding speed for the contact frequencies ranging from 1 to $2 \mathrm{~Hz}$, and then from 3 to $7 \mathrm{~Hz}$, this dependence starts to attenuate with the sliding speed. These results indicate that, for contact frequencies below $7 \mathrm{~Hz}$, the wear rate depends on the sliding speed, although they do definitely not follow an inverse reciprocal relationship as it might be expected from Quinn's model for oxidative wear $[10,12,13]$.

However, at contact frequencies above $7 \mathrm{~Hz}$, the wear rate behaves differently with increasing sliding speed. The wear rate gradually decreases as the sliding speed increases. In this case, the data displayed at steady contact frequencies higher than $7 \mathrm{~Hz}$ exhibits the expected behaviour from the Quinn's model.

It can also be observed that the wear rate values measured remain below $21.1 \cdot 10^{-4}$ $\mathrm{mm}^{3} / \mathrm{N} \cdot \mathrm{m}$. In particular, at the low contact frequency range, e.g. $1 \mathrm{~Hz}$, the wear rate increases from $2.39 \cdot 10^{-4}$ to $11.2 \cdot 10^{-4} \mathrm{~mm}^{3} / \mathrm{N} \cdot \mathrm{m}$. Whilst at $16 \mathrm{~Hz}$, the highest contact frequency tested, the wear rate diminishes from $13.1 \cdot 10^{-4}$ to $5.99 \cdot 10^{-4} \mathrm{~mm}^{3} / \mathrm{N} \cdot \mathrm{m}$. 
As aforementioned, the Eq. (2) directly relates the sliding speed and the contact frequency by adjusting the wear track diameter, i.e. the length of the wear track, $\pi \cdot D$. Therefore, a given total sliding length leads to a different number of cycles in function of the wear track diameter. In other words, for a given sliding distance the ball passes a different number of times over each point on the track depending on the wear track diameter. Consequently, one might think that the number of cycles or number of interactions between the ball and each point of the wear track can be a possible parameter which determines the wear rate along the total sliding distance. At this point, it may be thus interesting to calculate the wear rate as the wear volume loss per unit contact load and per number of cycles, in order to clarify that effect.

The newly defined wear rate is thus represented as a function of the contact frequency (Fig. 13) and also as the sliding speed (Fig. 14). Noticed is the similar wear behaviour, regardless the wear rate definition, i.e. expressed per total sliding distance (Fig. 11-12) or per number of cycles (Fig. 13-14).

It can be observed in Fig. 13 that the wear rate tested at six fixed sliding speeds decreases as the contact frequency increases. This diminishing is gradually smoother as the given sliding speed grows, as occurs in Fig. 11. The wear rate evolution as the sliding speed increases at nine fixed contact frequencies is presented in Fig. 14. Likewise as observed in Fig. 12, the wear behaviour is more complex. Firstly, the wear rate steeply increases when the fixed contact frequencies vary between 1 and $7 \mathrm{~Hz}$. Then at $9 \mathrm{~Hz}$ the wear rate attenuates its evolution with the sliding speed. Finally, at contact frequencies above $9 \mathrm{~Hz}$, the wear rate gradually decreases with increasing the sliding speed.

Therefore, the wear rate seems to depend on the contact frequency and on the sliding speed. However, it does not rely on the number of cycles, i.e. the wear track diameter.

\subsection{Validity of the Garcia-Ramil-Celis model for discontinuous sliding contact events on DP600 steels}

In the present work, the wear rate values obtained differ from those found in the literature due to the fact that in most of the work published, the rotation speed was chosen as a constant when performing tests at different sliding speeds. In these cases, a change in the sliding speed also causes variation in the contact frequency. As a result, it 
is then not possible to distinguish the effect of sliding speed and contact frequency on the wear rate of the disc made of the material under study.

As was previously observed, the results presented in Fig. 12 do not follow a consistent inverse reciprocal relationship between the wear rate and the sliding speed in the entire range for the fixed contact frequencies given, as is expected from Quinn's mild oxidation wear model (see Eq. (1)), since below $7 \mathrm{~Hz}$ the wear rate increases with increasing sliding speed.

Moreover, the effect of the contact frequency on the wear rate, experimentally determined in the present work (Fig. 11), is hardly explained via Quinn's model when it is applied to the disc.

This model was developed in order to describe the wear of a pin, which is in continuous sliding contact with a disc. However, as can be seen in the literature, this model has been widely applied indistinctively for the counterbody -the pin or ball-, in continuous contact, or the specimen -the disc- which are in discontinuous sliding contact with the ball.

In order to overcome this limitation, Garcia et al. [18] proposed a modification to Quinn's model to explain the wear behaviour for discontinuous sliding contact events. This new model is thus applicable to the wear of the discs in pin/ball-on-disc wear tests.

It should be noticed here that either Quinn's or Garcia's model have been developed assuming oxidative wear of single-phase materials. Tyagi et al. [45] proposed an extension of Quinn's model for materials with two phases, studying specifically dualphase steels and considering several possibilities about the kinetics of the oxidation, the critical thicknesses of the oxide layers and the probabilities of their removal. The authors concluded that the two phases, ferrite and martensite, usually have the same oxidation behaviour and also similar critical thicknesses for oxidative wear. Consequently, Quinn's model and its subsequent modifications for oxidative wear, e.g. Garcia et al. [18], are assumed to be also applied for two phase materials.

The expression for the volumetric wear loss of a disc material, $W$, in Garcia-Ramil-Celis model [18] leads to the following:

$$
W=\frac{A_{c} \exp \left(-Q / R T_{f}\right)}{\xi^{2} \rho^{2} f} \frac{F}{H} L
$$


where $\xi$ is the critical oxide thickness, $\rho$ the density, $f$ the contact frequency, $H$ the hardness of the material tested, $F$ the normal load applied, $L$ the sliding distance, $R$ the gas constant, $T_{f}$ the local temperature in the asperities, $A_{c}$ the activity factor, and $Q$ the Arrhenius activation energy for oxidation.

Moreover, the authors stated a simplification of the equation for disc surface flash temperature, $T_{f}$, in discontinuous contact with a pin or ball, by computing the heat transmission equation (see Appendix A, [18]):

$T_{f}=\tau v^{1 / 2}$

where $\tau$ contains all the parameters not related to either sliding speed or contact frequency.

Fig. 15 shows the obtained data from Fig. 11, i.e. wear rate as a function of the contact frequency, simulated with Eq. (8) and, using expression (9) for $T_{f}$. A suitable fit is given for the wear rate of the DP600 steel disc material. This fit relies on two parameters, which are kept fixed for the sliding speeds, namely:

$P_{1}=\frac{A_{c}}{\xi^{2} \rho^{2}}\left(\frac{1}{H}\right), \quad P_{2}=\frac{Q}{R \tau}$

The $P_{1}$ and $P_{2}$ parameter values chosen for the fitting process were those found which best describe the experimental data, generating a curve closely resembled to them. Using these values, an iterative procedure started. Similar $P_{1}$ and $P_{2}$ values were obtained for all the fixed sliding speed range tested. Therefore, P1 y P2, can be considered as a constant.

Subsequently, the two constant values obtained for $P_{1}$ and $P_{2}$ from fitting the data in Fig. 15 were also used to simulate the experimental data displayed in Fig. 12, for each of the contact frequencies. In this sense, Fig. 16 presents the assessed predicted data and the experimental values (Fig. 12) for the wear rate of the disc material as a function of the sliding speed. Initially, below $7 \mathrm{~Hz}$ (Fig. 16 (a)), the predicted data fit the experimental data properly. From $7 \mathrm{~Hz}$ onwards (Fig. 16 (b)), these theoretical data visibly mismatch with the experimental data.

The wear rate values exhibited as a function of the sliding speed for fixed contact frequencies above $7 \mathrm{~Hz}$ are expected to be in better concordance with the wear 
behaviour exposed in Quinn's model, due to the inversely reciprocal wear behaviour of the DP600 steel disc material shown in Fig. 12. Therefore, a new fitting procedure was carried out, using Eq. (1), i.e. Quinn's model expression for volumetric wear loss, and a different expression for the flash temperature.

Based on Cowan and Winer work [46], the flash temperature expression for a pin/ball in elastic contact sliding against a disc leads to as follows:

$T_{f}=0.13 \mu\left(\frac{1}{k}\right)\left(\frac{E}{R}\right)^{1 / 3} F^{2 / 3} v$

where $\mu$ is the coefficient of friction, $k$ the thermal conductivity, $E$ the Young's modulus, $R$ the pin/ball radius, $F$ the load applied, and $v$ the sliding speed.

The flash temperature, therefore, is directly dependent on the sliding speed. This expression was specifically proposed for permanent contact conditions, typically prevailed on pins/balls for pin/ball-on-disc wear tests, respectively.

Fig. 17 thus presents the wear rate values shown in Fig. 12, but only focused on the fixed contact frequencies range from 9 to $16 \mathrm{~Hz}$, whose experimental data are on this occasion fitted by Eqs. (1) and (11). It can be noticed that the simulated data, estimated via Quinn's model, fit the experimental data properly and better than using the GarciaRamil-Celis model.

The Arrhenius activity factor, $A_{c}$, and the activation energy value, $Q$, have to be treated as adjustable parameters, chosen to fit data wear rate [2]. The Arrhenius constant, can be calculated from the fit parameter $P_{l}$, assuming a certain critical thickness for the oxides obtained, $\xi$, the hardness, $H$, and the density, $\rho$, of these oxides; and from the debris diameter [18]. On the other hand, the activation energy values can be obtained from the fit parameter $P_{2}$. In the present work, either the wear mechanism behaviour or the type of debris generated on the DP600 steel disc material make the Arrhenius activity factor difficult to calculate. Moreover, the uncertainties about $\tau$ (Eq. (9)) complicate the estimation of the activation energy factor.

\section{Discussion}


The prior results suggest that the contact frequency of the counterbody with a given part of the wear track on the disc seems indeed to be a key parameter affecting the COF and the wear rate.

In the present work, under sliding wear conditions, DP600 steel exhibits a mild oxidation wear, showing a change in the nature of the oxide grown during sliding as a function of sliding speed and contact frequency. The two main types of oxidised debris collected are $\mathrm{Fe}_{2} \mathrm{O}_{3}$ and $\mathrm{Fe}_{3} \mathrm{O}_{4}$. This variation in the iron oxide form is attributed to a significant change in the temperature $[47,48]$. The oxide $\mathrm{Fe}_{2} \mathrm{O}_{3}$ retrieved is the expected oxide found when a low temperature below $450^{\circ} \mathrm{C}$ is reached. Whilst, $\mathrm{Fe}_{3} \mathrm{O} 4$ is an oxide usually found when the temperature range reached during sliding is between $450^{\circ} \mathrm{C}$ and $600^{\circ} \mathrm{C}[11,40,41,44,49]$. Kayaba et al. [50] similarly supported these results by associating a reduction in the COF and the wear rate with increasing the temperature with the variation in the iron oxide from $\mathrm{Fe}_{2} \mathrm{O}_{3}$ to $\mathrm{Fe}_{3} \mathrm{O}_{4}$. Several authors $[51,52]$ assumed that the diminishing in the COF and the wear rate at elevated temperatures is related to the formation of $\mathrm{Fe}_{3} \mathrm{O}_{4}$ which is thought to behave as a better solid lubricant than $\mathrm{Fe}_{2} \mathrm{O}_{3}$ due to its ability to adhere more strongly to the surface.

The demonstrated role of the contact frequency when studying the wear behaviour for a disc leads to the idea that the influence of the sliding speed on the type oxide grown is probably overshadowed by the contact frequency effect, due to its effect on the friction energy, and thus on the local contact temperature.

At this point it should be recalled that, as it is well-known in unidirectional pin-on-disc or ball-on-disc wear tests, the heat originated by friction contact at the pin/ball asperities is continuously generated due to these asperities are assumed to always be in contact with the disc asperities during the test. On the contrary, the frictional heat at the disc surface is only generated per rotation, i.e. during the time in contact time between the asperities from the disc and the counterbody. This frictional heat is generated at any point of the disc along the pin/ball trajectory and can be simulated as a square wave function [18], where the frictional heat, $q$, per unit of nominal contact area, $A_{n}$, per second is defined as follows [53]:

$q=\frac{\mu F v}{A_{r}}$ 
$\mu$ being the coefficient of friction, $F$ the normal load, $v$ the sliding speed, and $A_{r}$ the real contact area.

When the pin/ball slides against the disc, the ffriction turns into heat at their interfaces, and also tends to flow through both bodies, in varying ways, depending on their thermal properties. The resulting rise in temperature make then modify the mechanical and metallurgical properties of the sliding surfaces, and it makes them oxidize, thus influencing the wear rate [2].

It should be noticed that the literature is somewhat ambiguous on the application of Quinn's mild oxidation wear model in the case of unidirectional pin or ball-on-disc sliding wear tests. The contact conditions prevailing at the pin or ball surface, and at the disc surface are indeed different. At a macroscopic level, the pin or ball surface is in permanent contact with the disc during the sliding. Conversely, each segment of the wear track on the disc is only loaded for a limited time in between successive contact events. Therefore, the wear rate for a given material is thus different, depending on whether the material acts as disc or pin/ball material [18].

Likewise, in Garcia-Ramil-Celis model, the elapsed time in between successive contact events is more important than the contact time duration for these events. Furthermore, the time required to reach the critical oxide thickness depends on the contact frequency, which is expressed as the inverse of the elapsed time in between two contacts at a given point.

The disagreement between the experimental and the fitting performed using GarciaRamil-Celis model above $7 \mathrm{~Hz}$ (Fig. 16 (b)) may be related to the apparent contact frequency at a specific point of the wear track on the DP600 steel disc. In this work, therefore, it is assumed that the frictional heat at the disc surface is only generated during the contact time in between the asperities from the disc and the pin/ball, following a square wave function and depending on an inverse reciprocal relationship between the elapsed time and the contact frequency.

As the contact frequency increases, the elapsed time in between two successive frictional heat inputs notably decreases to such an extent, that the square wave function which describes the heat generated by friction, tends to convert into a type of constant linear function. 
On account of this, by increasing the contact frequency, the elapsed time decreases during the contact intervals between the ball and a certain point of the disc. As the test runs, a certain temperature, defined by a compromise between the constant energy input and the heat diffusion, is reached. As a result each point of the disc starts to heat up under a condition that becomes close to a continuous contact similar to the condition observed by the ball. At this point, the wear rate behaviour is more similar to the predicted behaviour in the Quinn's model for continuous sliding contact events of two bodies in frictional sliding movement, which is clearly observed in Fig 16, where the experimental data fit correctly with the theoretical data simulated via Quinn's model.

\section{Conclusions}

The friction and wear behaviour of the DP600 steel discs sliding against corundum balls have been evaluated at several sliding speeds while maintaining the contact frequency at a steady value; but also at various contact frequencies thus keeping the sliding speed constant. These experimental conditions allow us to demonstrate that the wear rate of DP600 steel discs relies not only on the sliding speed of the ball on the disc, but also on the contact frequency.

The wear mechanism of the DP600 is mild oxidation wear. The nature of the iron oxide debris is a function of the sliding speed and the contact frequency. At low contact frequencies the predominant oxide is $\mathrm{Fe}_{2} \mathrm{O}_{3}$, while at high contact frequencies the oxide formed is mainly $\mathrm{Fe}_{3} \mathrm{O}_{4}$.

The COF diminishes with the contact frequency. The COF behaves distinctly with the sliding speed. Initially, the COF increases with the increase of the sliding speed, and then the COF decreases gradually with the increase of the sliding speed.

The wear behaviour is, however, more complex. For the contact frequencies below 7 $\mathrm{Hz}$, the wear mechanism suitably fit Garcia-Ramil-Celis model as a consequence of the discontinuous sliding contacts. On the other hand, for contact frequencies above $7 \mathrm{~Hz}$, the wear mechanism is visibly in concordance with Quinn's model.

The present work demonstrates the importance of considering the contact frequency as an independent parameter, together with the contact load and the sliding speed, when wear features for materials that are subjected to discontinuous sliding contacts are tested and/or described. 
In pin/ball-on-disc wear tests, the pin/ball and the disc have to be considered differently. Consequently, this necessary distinction between the bodies of the tribological pair $\mathrm{pin} / \mathrm{ball}$ and disc- should always take into account whether the contact conditions are continuous and discontinuous due to the ball is in continuous contact with the disc, but conversely each given point of the disc wear track is in discontinuous contact with the ball.

\section{Acknowledgments}

The authors gratefully acknowledge the funding by Ministerio de Economía y Competitividad (MINECO) under project Innpacto IPT-020000-2010-020 and project CONSOLIDER-INGENIO 2010 CSD 2008-0023 FUNCOAT. 


\section{References}

[1] Zhang J, Alpas AT. Transition between mild and severe wear in aluminium alloys. Act Mat 1997;45:513-528.

[2] Lim SC, Ashby MF. Overview no. 55 Wear-Mechanism maps. Act Metal 1987; 35:1-24.

[3] Kato H, Eyre TS, Ralph B. Wear mechanism map of nitrided steel. Act Metal 1994; 42:1703-1713.

[4] Liu Y, Ashtana R, Rohaygi P. A map for wear mechanisms in aluminium alloys. J Mat Sci 1991;99-102.

[5] Burwell JT, Strang CD. On the empirical law of adhesive wear. J Appl Phys 1952; 23:18.

[6] Ludema K. Scuffing, run-in and the function of surface films, particularly oxides. Review paper for interdisciplinary collaboration in tribology project, NASA-Lewis; 1981.

[7] Tabor D. Wear- A critical synoptic view. Proc Int Conference on Wear of Materials, St. Louis, Missouri, April 1977, ASME; 1978, p.1-10.

[8] Quinn TF. The classifications, laws, mechanisms and theories of wear. Part VII of Fundamentals of Tribology. Editors N.P. Suh and N. Saka. The M.I.T; 1980:477-492.

[9] Archard JF, Hirst W. The wear of metals under unlubricated conditions. Proc Roy Soc (London), A236; 1956, p. 397.

[10] Quinn TFJ. Review of oxidational wear: Part I: The origins of oxidational wear. Tribol Int 1983;16:257-271.

[11] Quinn TFJ, Rowson DM, Sullivan JL. Application of the oxidational theory of mild wear to the sliding wear of low alloy steel. Wear 1980;65:1-20.

[12] Quinn TFJ. Oxidational wear modelling: Part II. The general theory of oxidational wear. Wear 1994;175:199-208.

[13] Quinn TFJ. Oxidational wear modelling Part III. The effects of speed and elevated temperatures. Wear 1998;216:262-275.

[14] Quinn TFJ. The oxidational wear of low alloy steels. Tribol Int 2002;35:691-715.

[15] Godet M. The third-body approach: A mechanical view of wear. Wear 1984;100: 437-452.

[16] Fromhold AT. Theory of metal oxidation, Vol 1, Fundamentals, Elsevier, Amsterdam; 1976.

[17] Fehlner FP, Mott NF. Low temperature oxidation, Oxidation of metals, Vol 2; 1970, p. 56-99.

[18] Garcia I, Ramil A, Celis JP. A mild oxidation model valid for discontinuous contacts in sliding wear tests: role of contact frequency. Wear 2003;254:429-440.

[19] Navas C, Garcia I, Ye X, de Damborenea J, Celis JP. Role of contact frequency on the wear rate of steel in discontinuous sliding contact conditions. Wear 2006;260:10961103.

[20] Jiang J, Stack MM. Modelling sliding wear : From dry to wet environments. Wear 2006;261:954-965. 
[21] Reynier B, Phalippou C, Riberty P, Sornin J. Influence of a periodic latency on the impact/sliding wear damage of two PWR control rods and guide cards specimens. Wear 2005;259:1314-1323.

[22] Pritchard SB, Trowsdale AJ. Dual Phase Steel-High Strength Fasteners Without Heat Treatment Corus Construction and Industrial, U.K.; 2002, p.1-10.

[23] Sun S, Pugh M. Properties of thermomechanically processed dual-phase steels containing fibrous martensite. Mat Sci and Eng A 2002;335:298-308.

[24] Wu-rong W, Chang-wei H, Zhong-hua Z, Xi-cheng W. The limit drawing ratio and formability prediction of advanced high strength dual-phase steels. Mat \& Design 2011;32:3320-3327.

[25] Ozturk F, Toros S, Kilic S. Tensile and Spring-Back Behavior of DP600 Advanced High Strength Steel at Warm Temperatures. Jour of Iron and Steel Research, Int 2009; 16: 41-46.

[26] Ramazani A, Mukherjee K, Scwedt A, Goravanchi P, Prahl U, Bleck W. Quantification of the effect of transformation-induced geometrically necessary dislocations on the flow-curve modelling of dual-phase steels. Int Jour of Plast 2013;43:128-152.

[27] Hulka K. Dual phase and Trip Steels. ASM Metal Park Ohio; 2000, p. 1-4.

[28] Rashid MS. Dual Phase Steels. Ann Rev Mater Sci 1981;11:245-266.

[29] Cui X, Zhang H, Wang S, Zhang L, Ko J. Design of lightweight multi-material automotive bodies using new material performance indices of thin-walled beams for the material selection with crashworthiness consideration. Materials \& Design 2011;32: 815-821.

[30] Meng Q, Li J, Zheng H. High-efficiency fast-heating annealing of a cold-rolled dual-phase steel. Materials \& Design 2014;58:194-197.

[31] Han Q-h, Kang Y-l, Zhao X-m, LÜ C, Gao L-f. Microstructure and Properties of Mo Microalloyed Cold Rolled DP1000 Steels. Journal of Iron and Steel Research, Int 2011;18:52-58.

[32] Wang W, Li M, Zhao Y, Wei X. Study on stretch bendability and shear fracture of 800MPa dual phase steel sheet. Materials \& Design 2014;56:907-913.

[33] Wayne SF, Rice SL. The role of microstructure in wear of selected steels. Wear 1983;85:93-106.

[34] Blau PJ. An investigation of the unlubricated friction and wear break-in behavior of a dual-phase steel. Wear 1981;72:67-80.

[35] Sawa M, Rigney DA. Sliding behavior of dual phase steels in vacuum and in air. Wear 1987;119:369-390.

[36] Basak A, Reddy DC, Kanth DVK. Computer modeling of wear resistance for plain carbon steels. Mater Sci Technol 1998;14:776-782.

[37] Modi OP, Bashad BK, Jha AK, Dasgupta R, Yegneswaran AH. Low stress wear behaviour of 0.2 \%C steel: Influence of microstructure. Tribol Lett 2003;15:249-255.

[38] Tyagi R, Nath SK, Ray S. Dry sliding friction and wear in plain carbon dual phase steel. Metall Mater Trans A 2001;32:359-367.

[39] Abouei V, Saghafian H, Kheirandish S. Effect of microstructure on the oxidative wear behavior of plain carbon steel. Wear 2007;262:1225-1231. 
[40] Tyagi R, Nath SK, Ray S. Effect of Martensite Content on Friction and Oxidative Wear Behaviour of 0.42 Pct Carbon Dual-Phase. Metall and Mater Trans A 2002;33A: 3479-3488.

[41] Tyagi R, Nath SK, Ray S. Development of wear resistant medium carbon dual phase steels and their mechanical properties. Mater Sci and Technol 2004;20:645-652.

[42] Abouei V, Saghafian H, Kheirandish S. Dry Sliding Oxidative Wear in Plain Carbon Dual Phase Steel. Jour of Iron and Steel Research, Int 2007;14:43-48.

[43] Abouei V, Saghafian H, Kheirandish S, Ranjbar K. An investigation of the wear behaviour of 0.2\% C dual phase steels. Jour of Mater Proc Technol 2008;203:107-112.

[44] Sullivan JL, Quinn TFJ, Rowson DM. Developments in the oxidational theory of mild wear. Tribol Int 1980;13:153-158.

[45] Tyagi R, Nath SK, Ray S. Modelling of dry sliding oxidation-modified wear in two phase materials. Wear 2003;255:327-332.

[46] Cowan RS, Winer WO, in: P. Blau (Ed.), ASM Handbook 18, ASM International; 1992, p. 39-44.

[47] Hurricks PL. Fretting wear of mild-steel from room temperature to $200^{\circ} \mathrm{C}$. Wear 1972;19:207-229.

[48] Hurricks PL. Fretting wear of mild-steel from $200^{\circ} \mathrm{C}$ to $500^{\circ} \mathrm{C}$. Wear $1974 ; 30: 189$ 212.

[49] Sullivan JL, Athwal SS. Mild wear of a low alloy steel at temperatures up to 500 ${ }^{\circ} \mathrm{C}$. Tribol Int 1983;16:123-131.

[50] Kayaba T, Iwabuchi A. The fretting wear of $0.45 \% \mathrm{C}$ steel and austenitic stainless steel from 20 to $650^{\circ} \mathrm{C}$ in air. Wear 1981;74:229-245.

[51] Clark WT, Pritchard C, Midgley JW. Mild wear of unlubricated hard steels in air and carbon dioxide. Proc of the Instit of Mech Eng, Conference Proceedings 182; 1967, p. 97-105.

[52] Foley RT, Peterson MB, Zapf C. Frictional characteristics of cobalt, nickel, and iron as influenced by their surface oxide films. ASLE Trans 1963;6:29-39.

[53] Ashby MF, Abulawi J, Kong HS. Temperature maps for frictional heating in dry sliding, Tribol Trans 1991;34:577-587. 


\section{Figure captions}

Fig. 1. Representative optical micrograph of the corundum surface at the contact area when slides against a DP600 steel disc, magnification x200.

Fig. 2. SEM images of wear tracks morphology on the disc after sliding tests performed at (a) $1.20 \mathrm{~Hz}, 0.1 \mathrm{~m} / \mathrm{s}, 13.26 \mathrm{~mm}$ of radius; (b) $16 \mathrm{~Hz}, 0.9 \mathrm{~m} / \mathrm{s}, 8.95 \mathrm{~mm}$ of radius.

Fig. 3. EDS spectra of wear tracks on the disc after sliding tests performed at (a) 1.20 $\mathrm{Hz}, 0.1 \mathrm{~m} / \mathrm{s}, 13.26 \mathrm{~mm}$ of radius; (b) $16 \mathrm{~Hz}, 0.9 \mathrm{~m} / \mathrm{s}, 8.95 \mathrm{~mm}$ of radius.

Fig. 4. (a)-(b) SEM images and (c) EDS spectrum taken from debris collected after sliding tests performed at $1.20 \mathrm{~Hz}, 0.1 \mathrm{~m} / \mathrm{s}, 13.26 \mathrm{~mm}$ of radius.

Fig. 5. (a)-(c) SEM images and (d)-(e) EDS spectra taken from debris collected after sliding tests performed at $16 \mathrm{~Hz}, 0.9 \mathrm{~m} / \mathrm{s}, 8.95 \mathrm{~mm}$ of radius.

Fig. 6. XRD diffractograms of debris generated after sliding tests performed at (a) 1.20 $\mathrm{Hz}, 0.1 \mathrm{~m} / \mathrm{s}, 13.26 \mathrm{~mm}$ of radius and (b) $16 \mathrm{~Hz}, 0.9 \mathrm{~m} / \mathrm{s}, 8.95 \mathrm{~mm}$ of radius.

Fig. 7. Theoretical estimation of flash temperature values measured on the discs.

Fig. 8. Evolution of coefficient of friction as a function of sliding time.

Fig. 9. Coefficient of friction recorded between DP600 steel discs sliding against corundum balls as a function of contact frequency at six fixed sliding speeds.

Fig. 10. Coefficient of friction recorded between DP600 steel discs sliding against corundum balls as a function of sliding speed at nine fixed contact frequencies.

Fig. 11. Wear rate (per total sliding distance) of DP600 steel discs sliding against corundum balls as a function of contact frequency at six fixed sliding speeds.

Fig. 12. Wear rate (per total sliding distance) of DP600 steel discs sliding against corundum balls as a function of sliding speed at nine fixed contact frequencies.

Fig. 13. Wear rate (per number of cycles) of DP600 steel discs sliding against corundum balls as a function of contact frequency at six fixed sliding speeds.

Fig. 14. Wear rate (per number of cycles) of DP600 steel discs sliding against corundum balls as a function of sliding speed at nine fixed contact frequencies. 
Fig. 15. Experimental data displayed in Fig. 10 fitted by Eqs. (8) and (9).

Fig. 16. Experimental data presented in Fig. 11 fitted by Eqs. (8) and (9): (a) 1Hz-7 Hz, (b) $9 \mathrm{~Hz}-16 \mathrm{~Hz}$; based on fitting parameters derived from the fitting in Fig. 14.

Fig. 17. Experimental data presented in Fig. 11 fitted by Eqs. (1) and (11); from $9 \mathrm{~Hz}$ to16 $\mathrm{Hz}$.

\section{Table captions}

Table 1. Chemical composition of DP600 dual phase steel (\% wt.) 
Figure 1

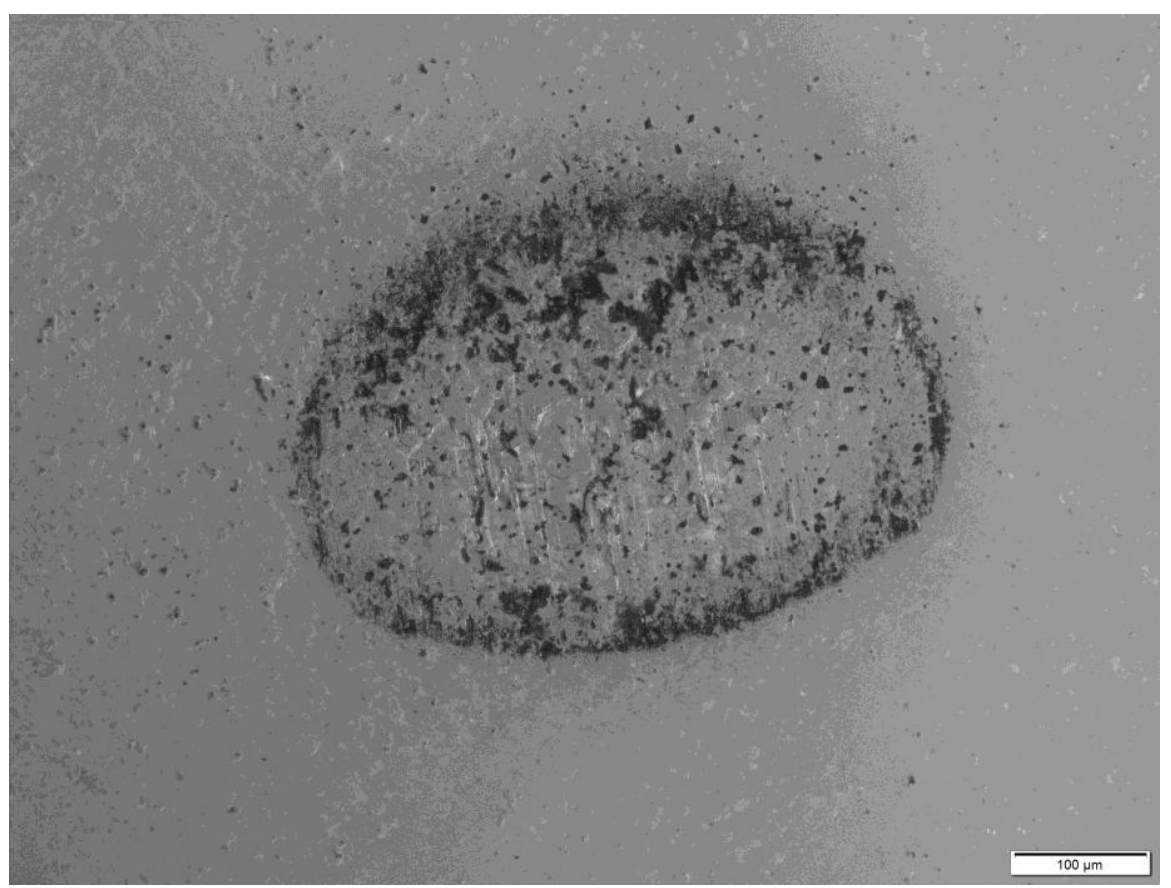


Figure 2
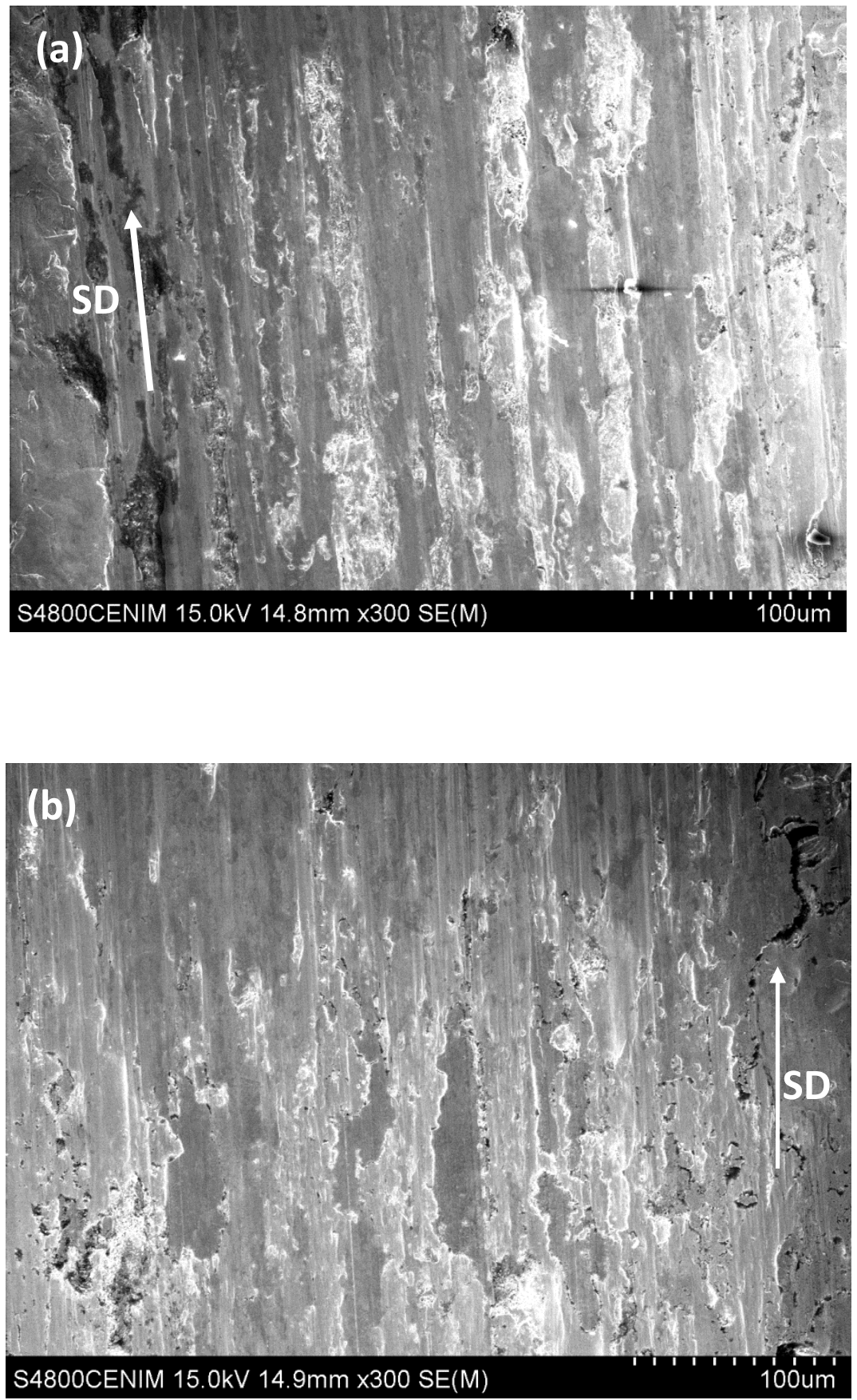
Figure 3

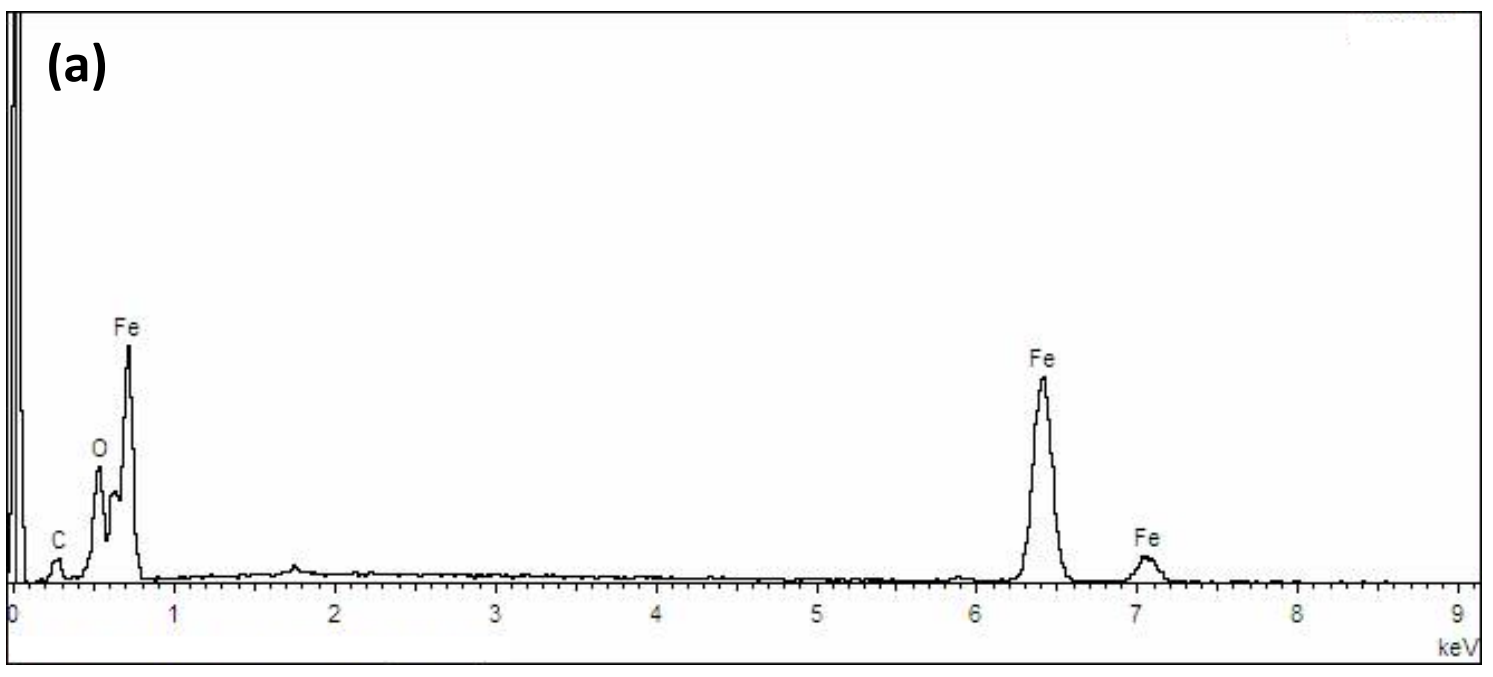

(b)

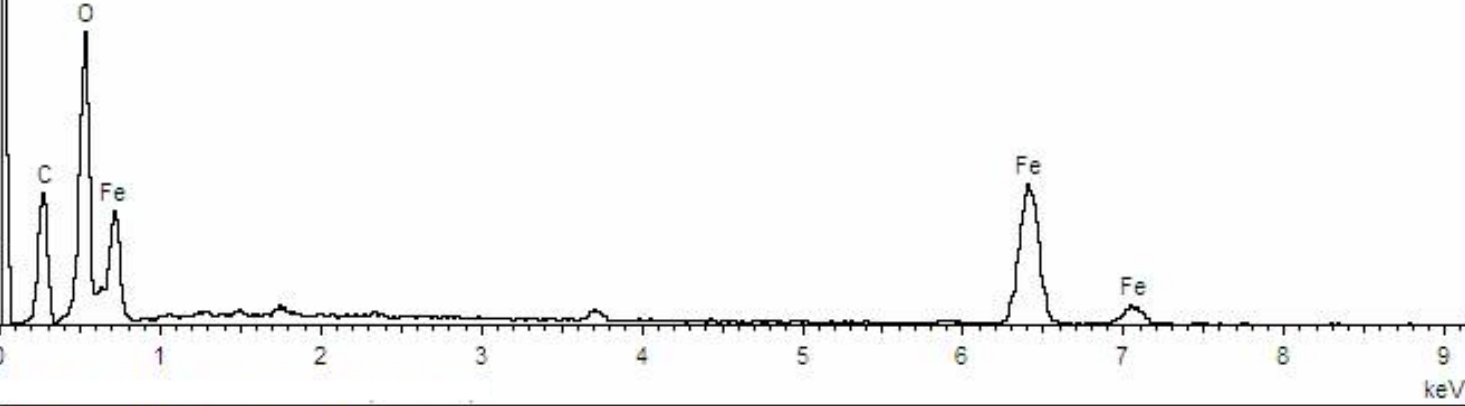


Figure 4
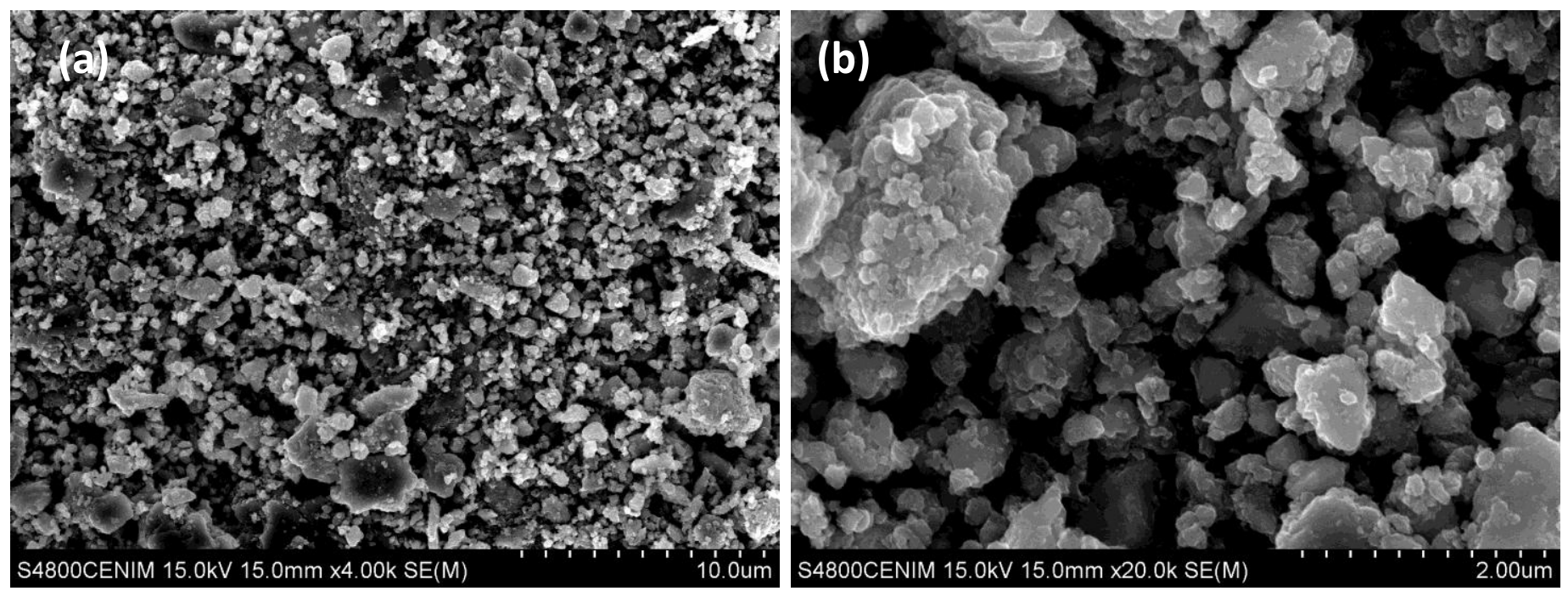

(c)

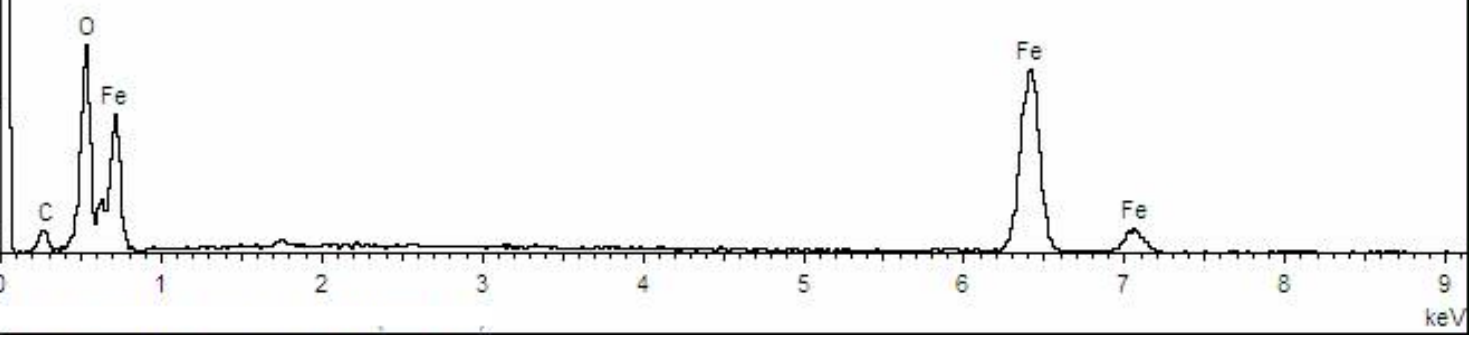


Figure 5
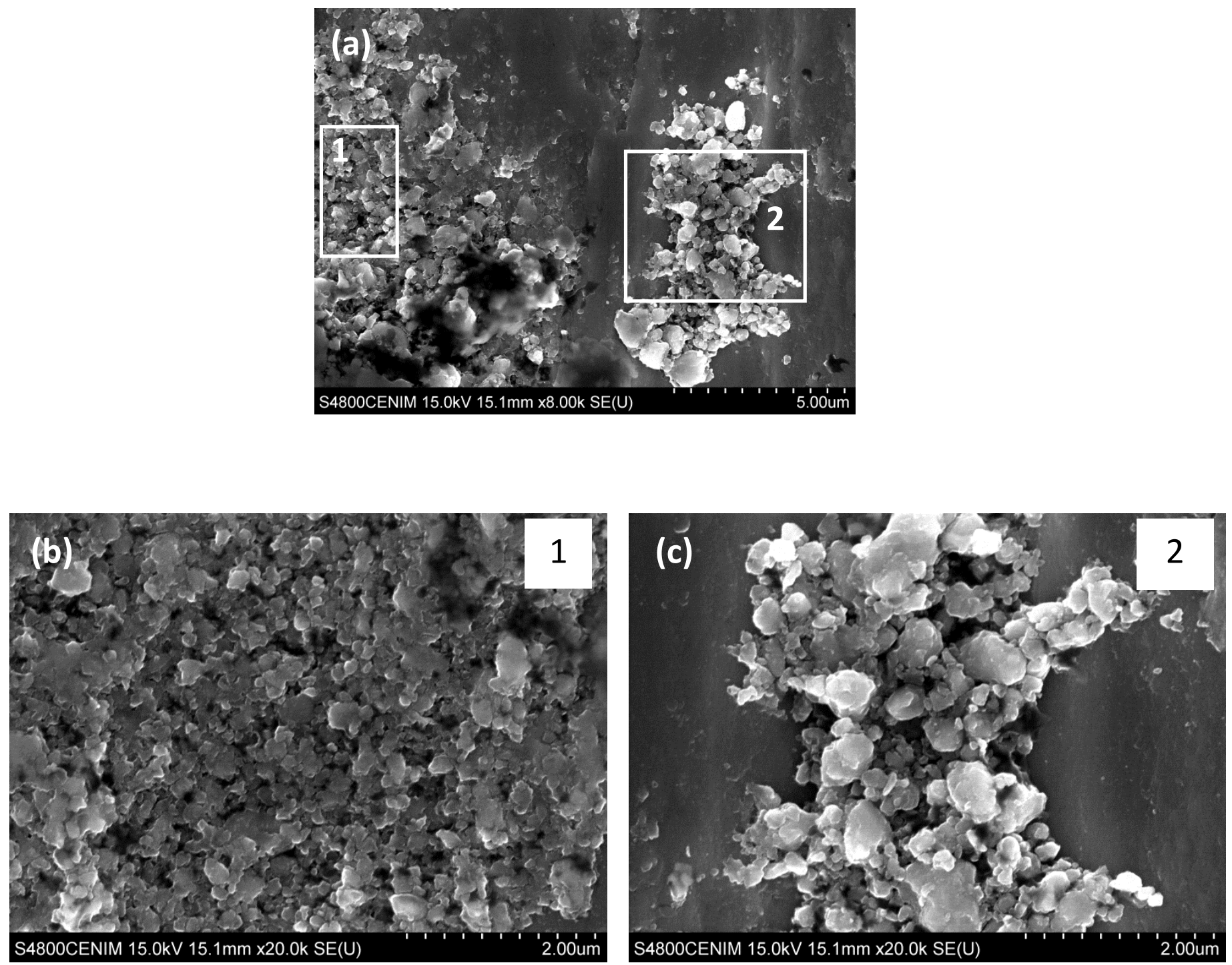

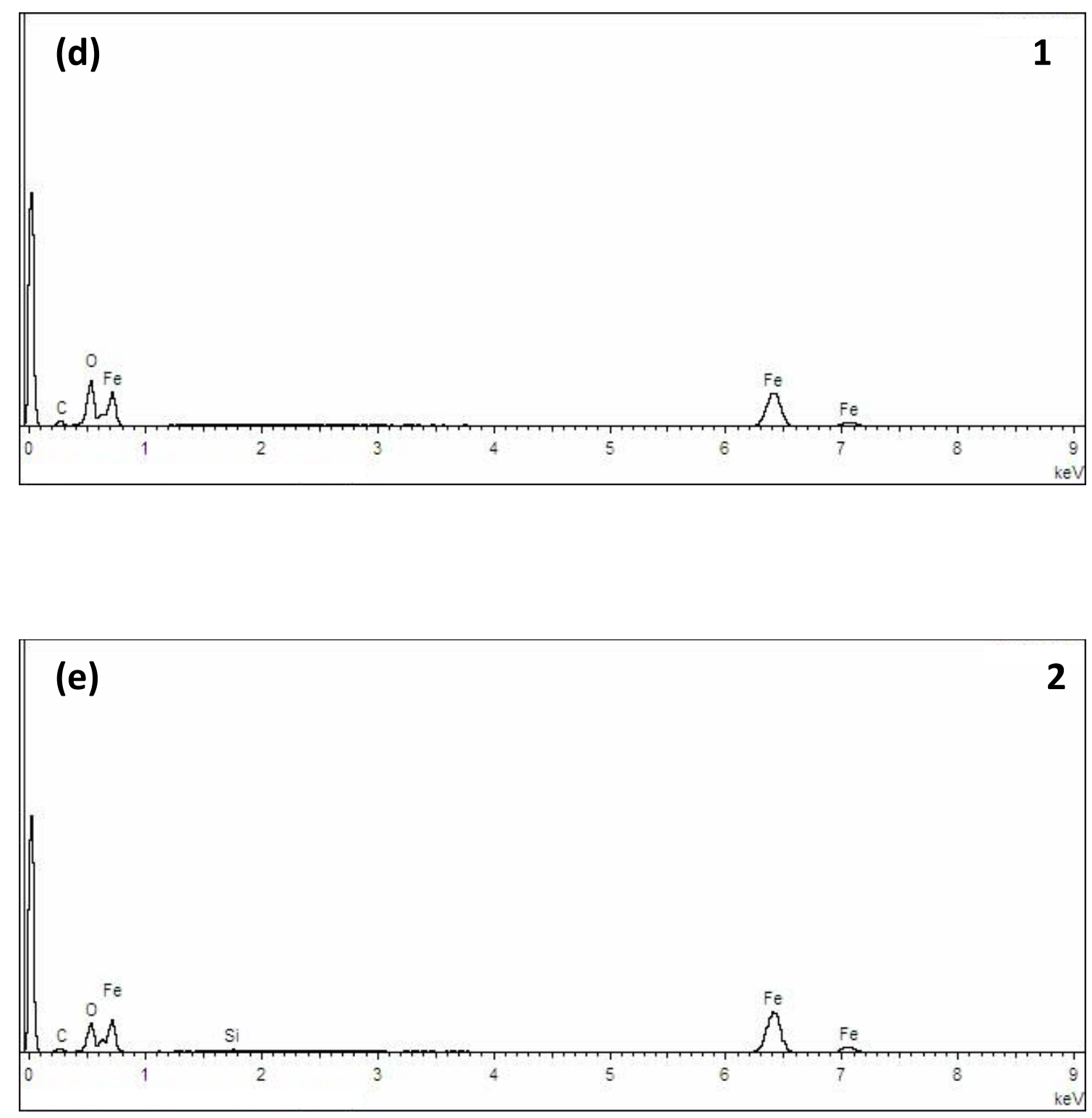
Figure 6
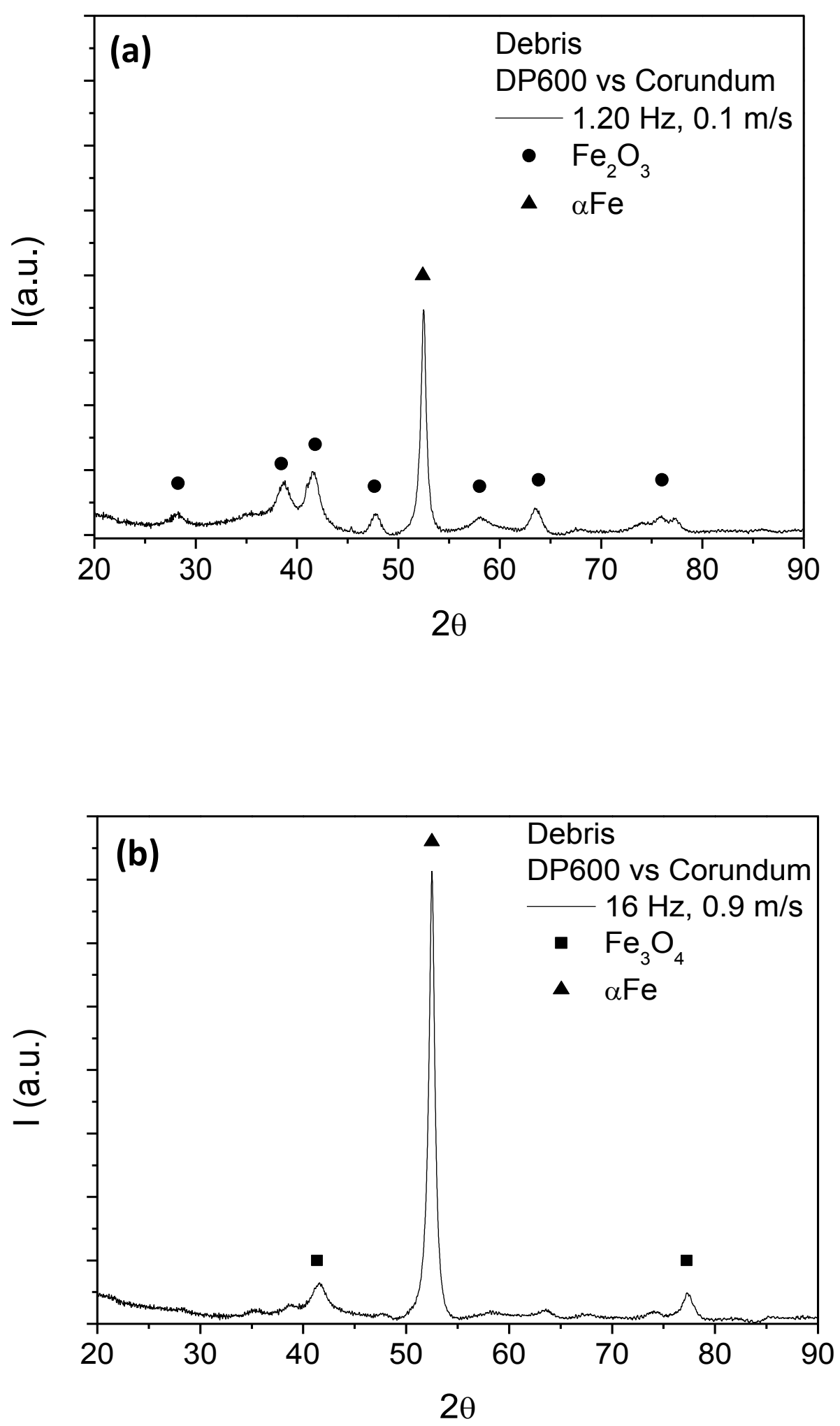
Figure 7

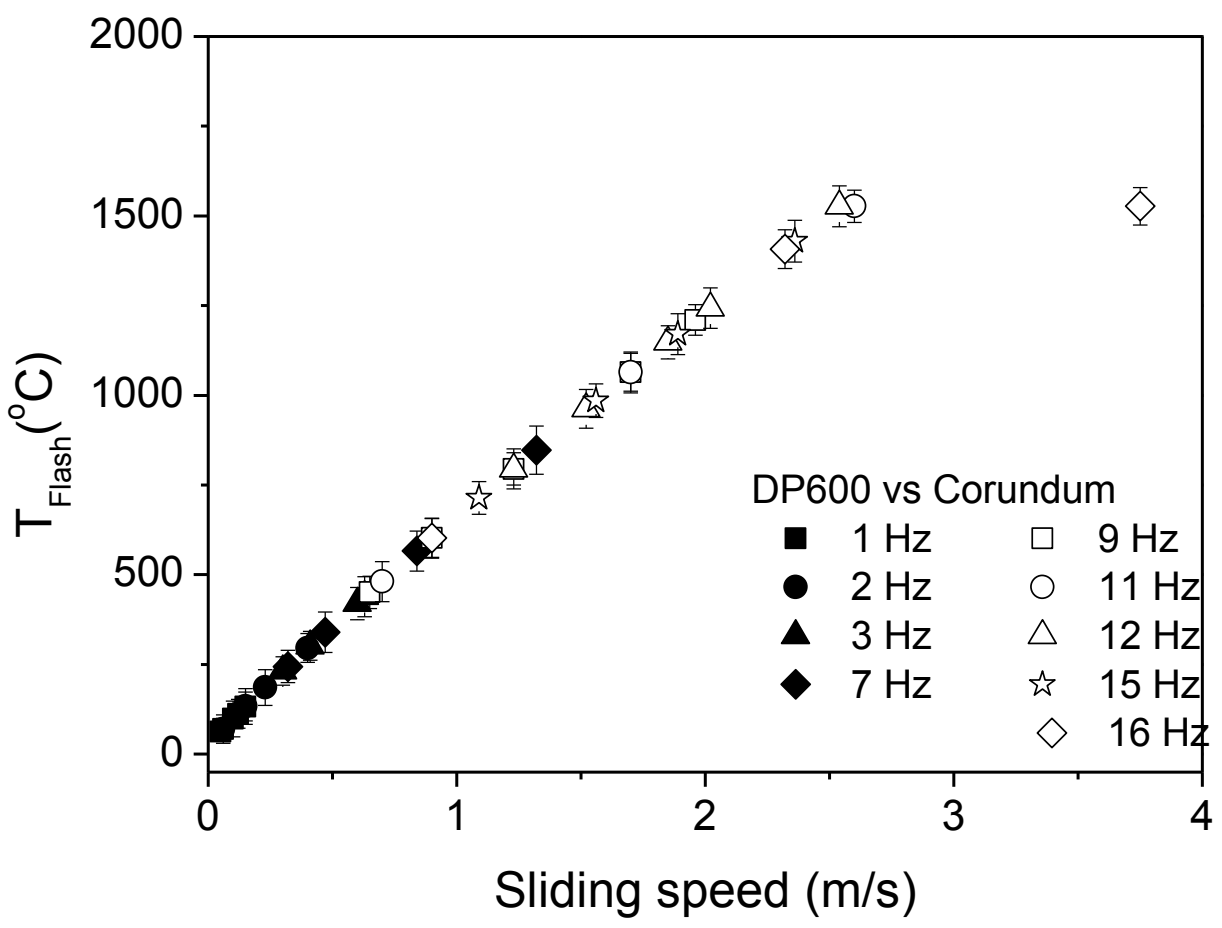


Figure 8

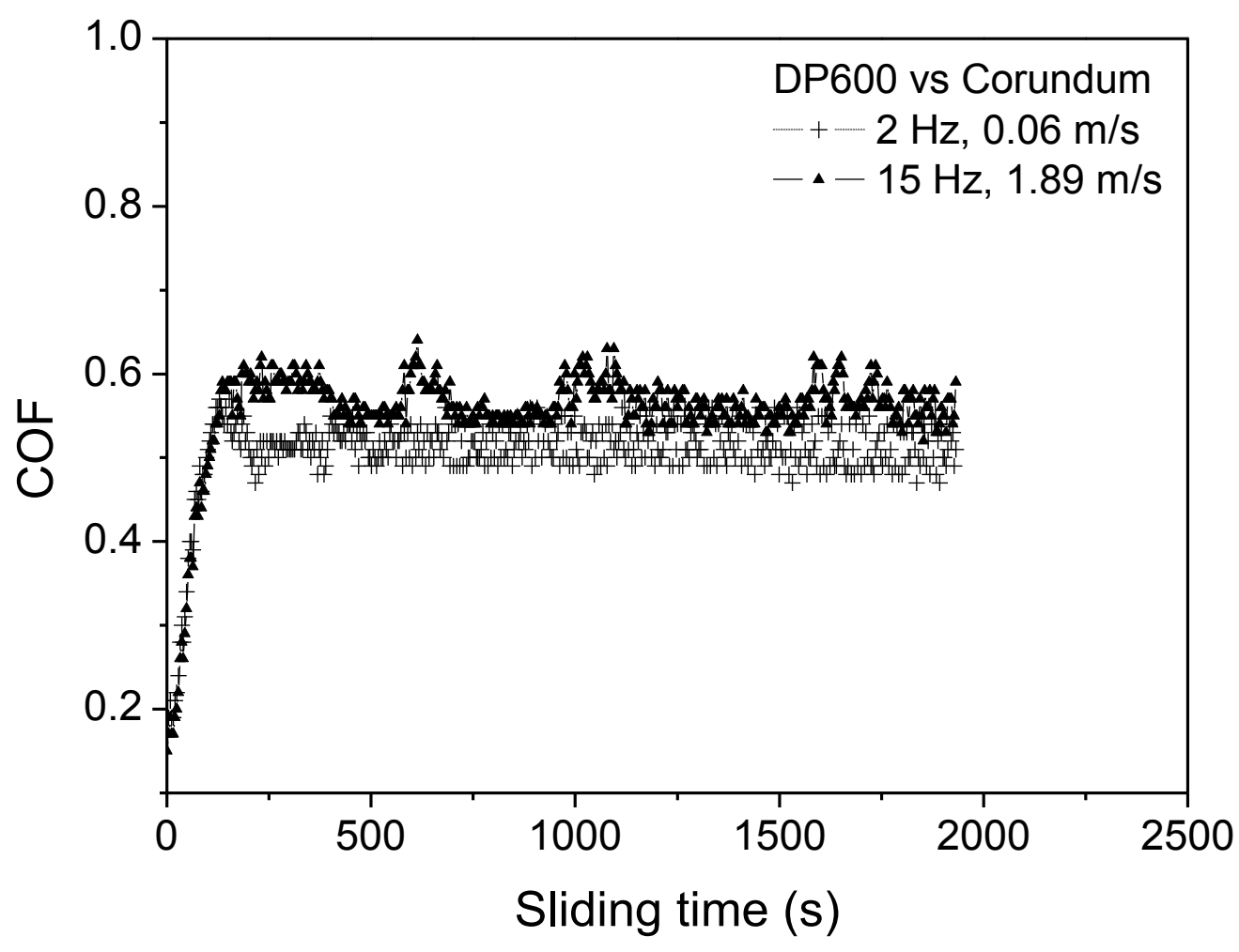


Figure 9

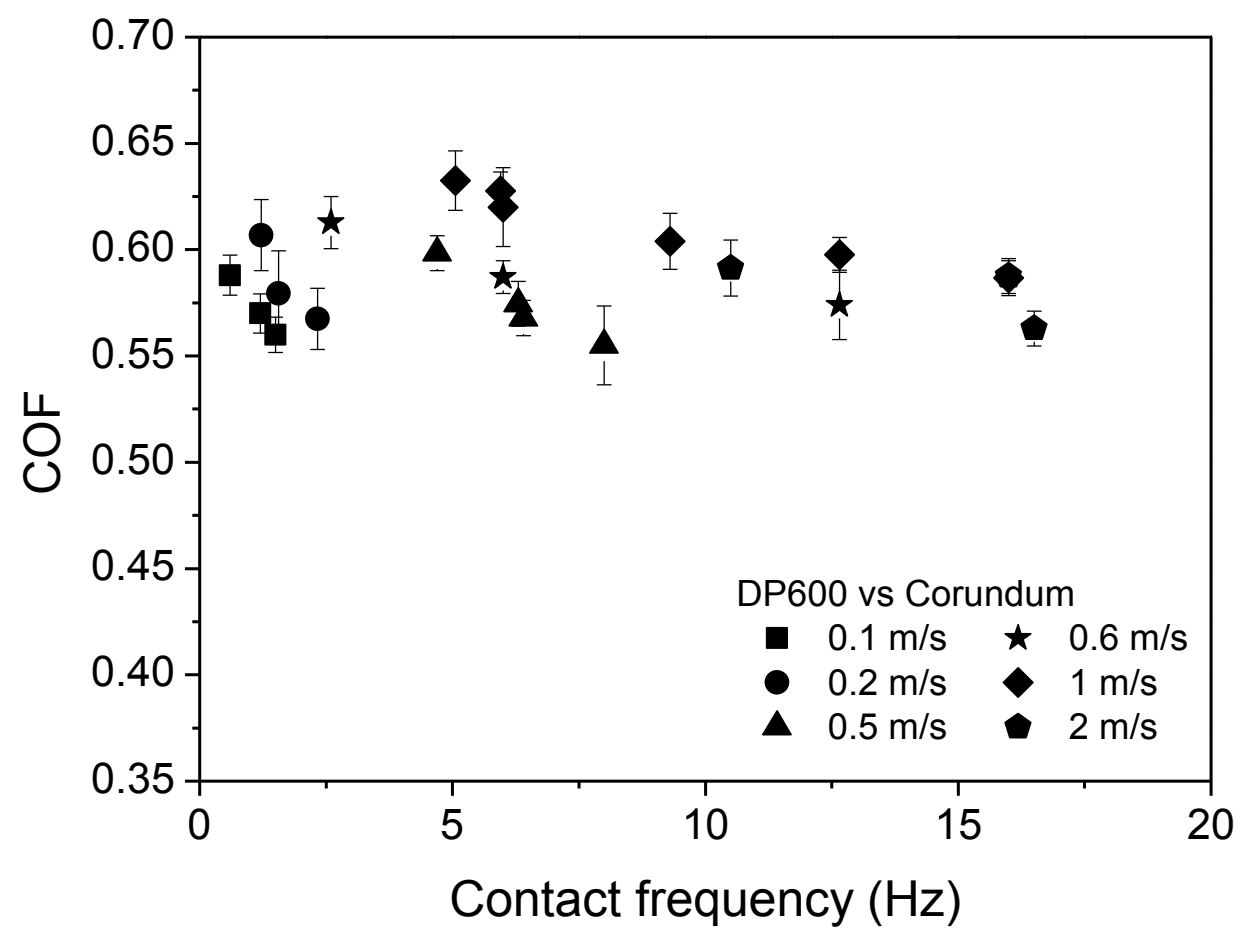


Figure 10

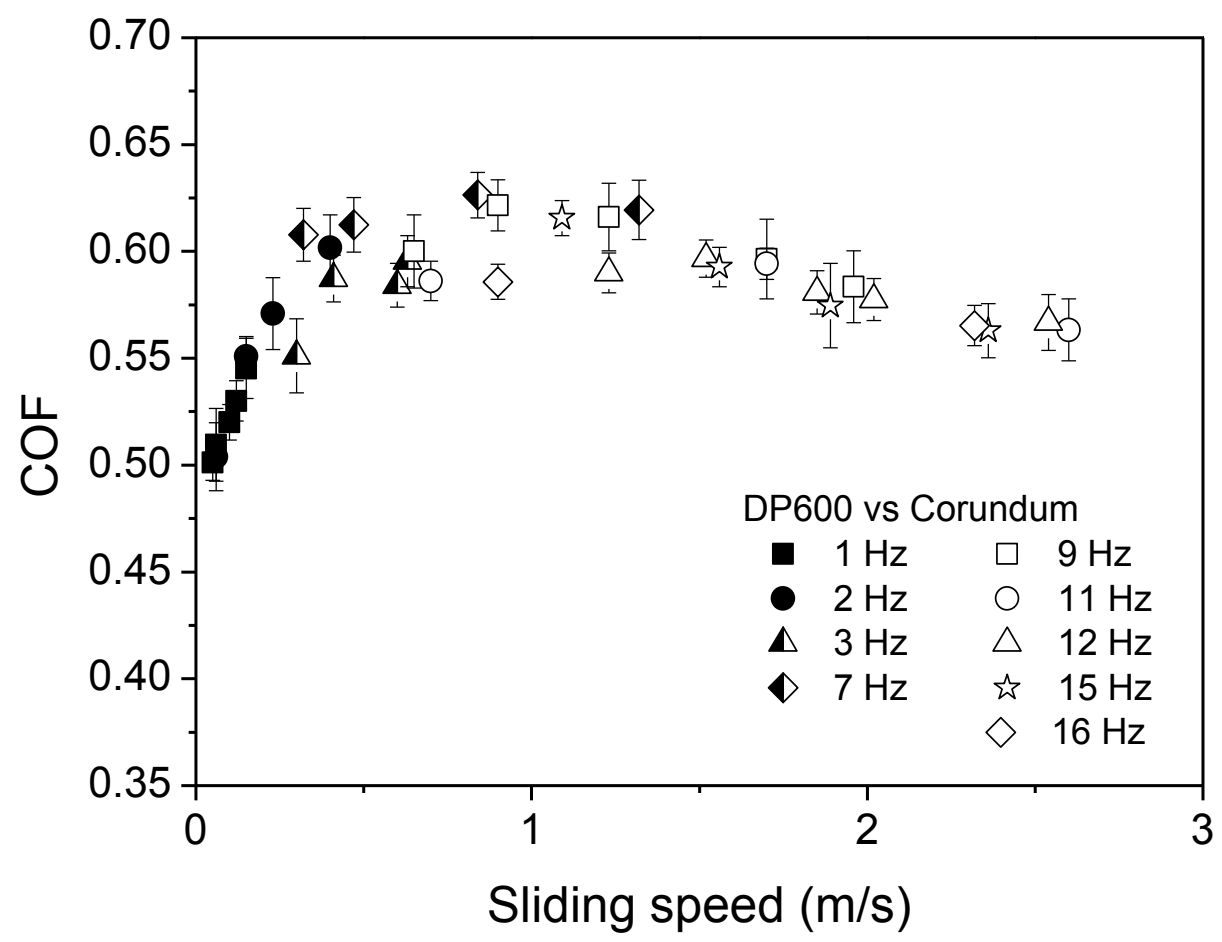


Figure 11

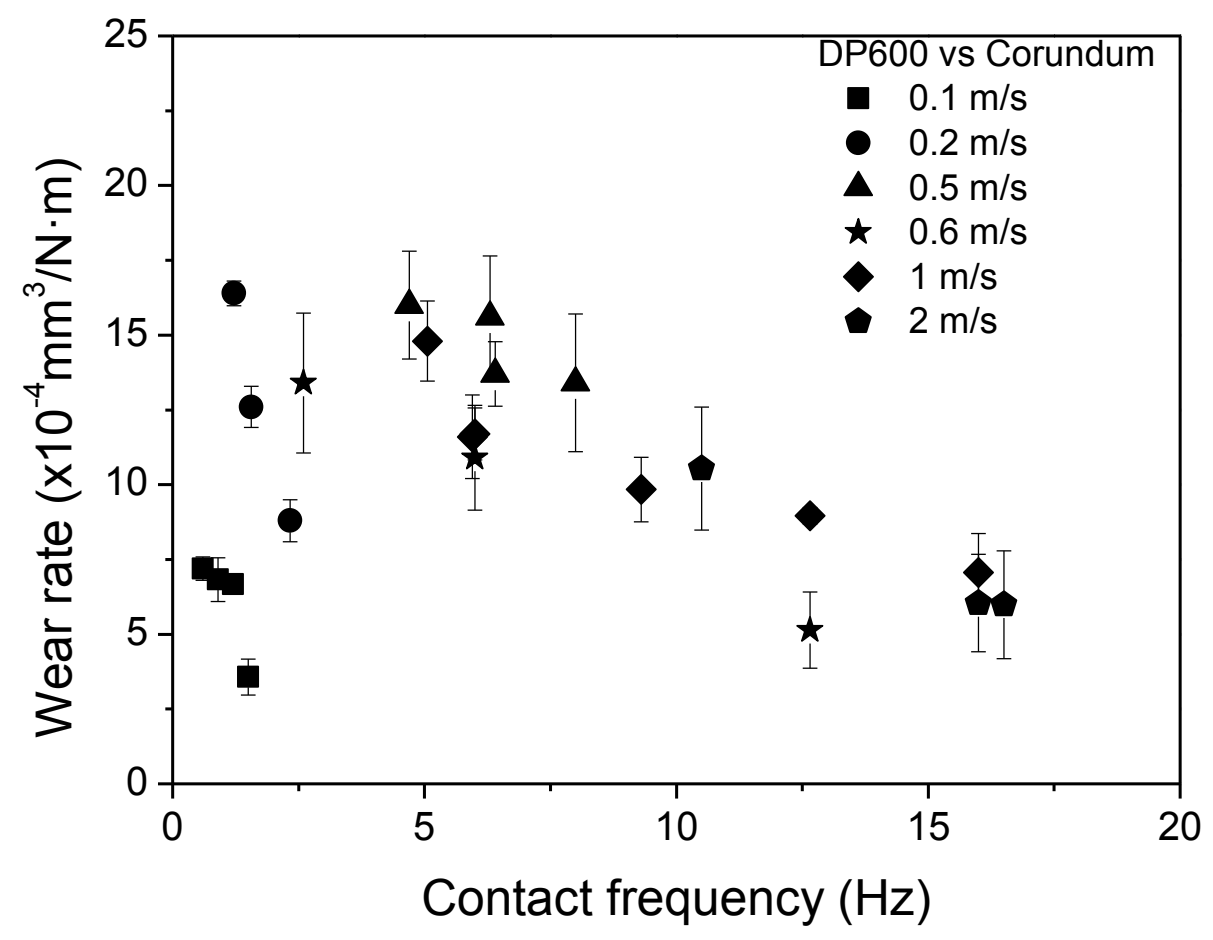


Figure 12

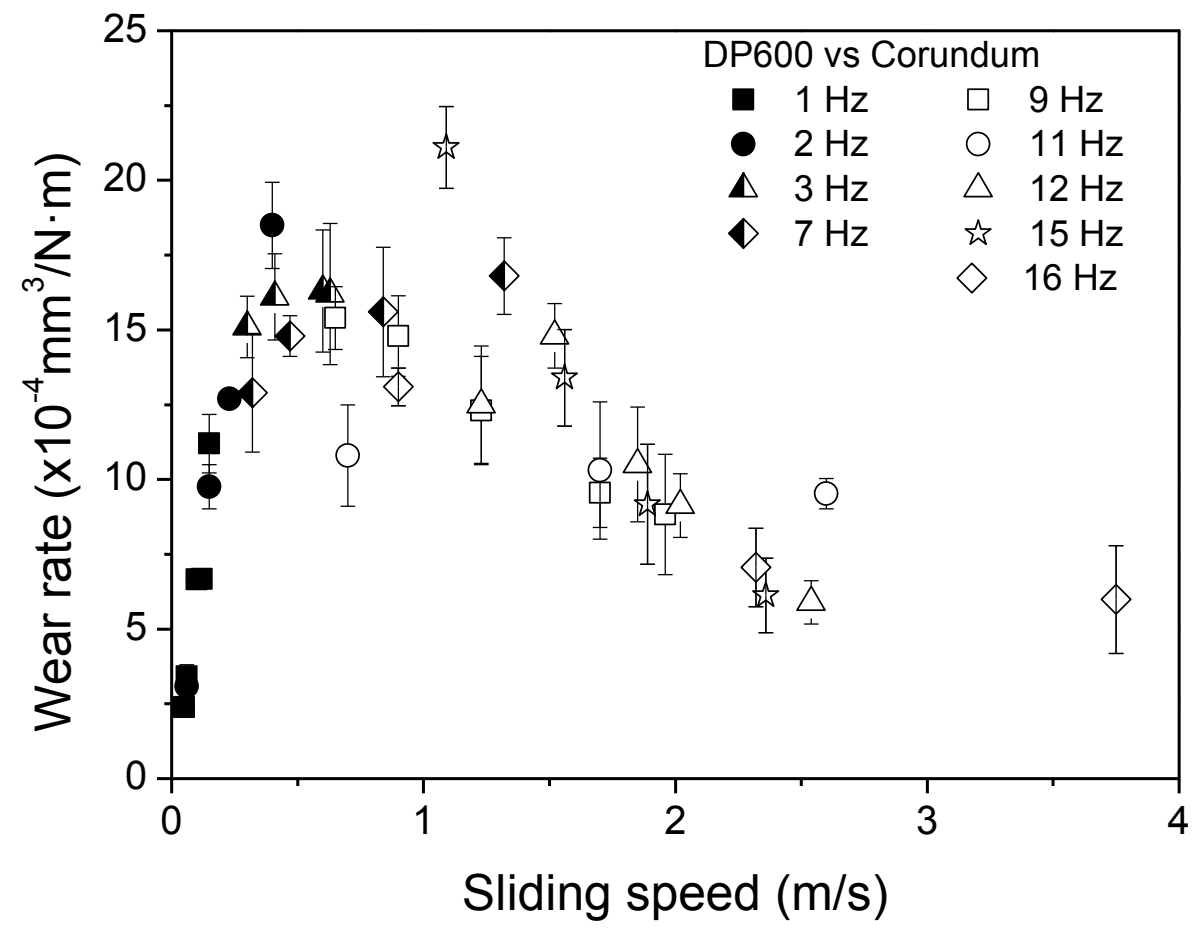


Figure 13

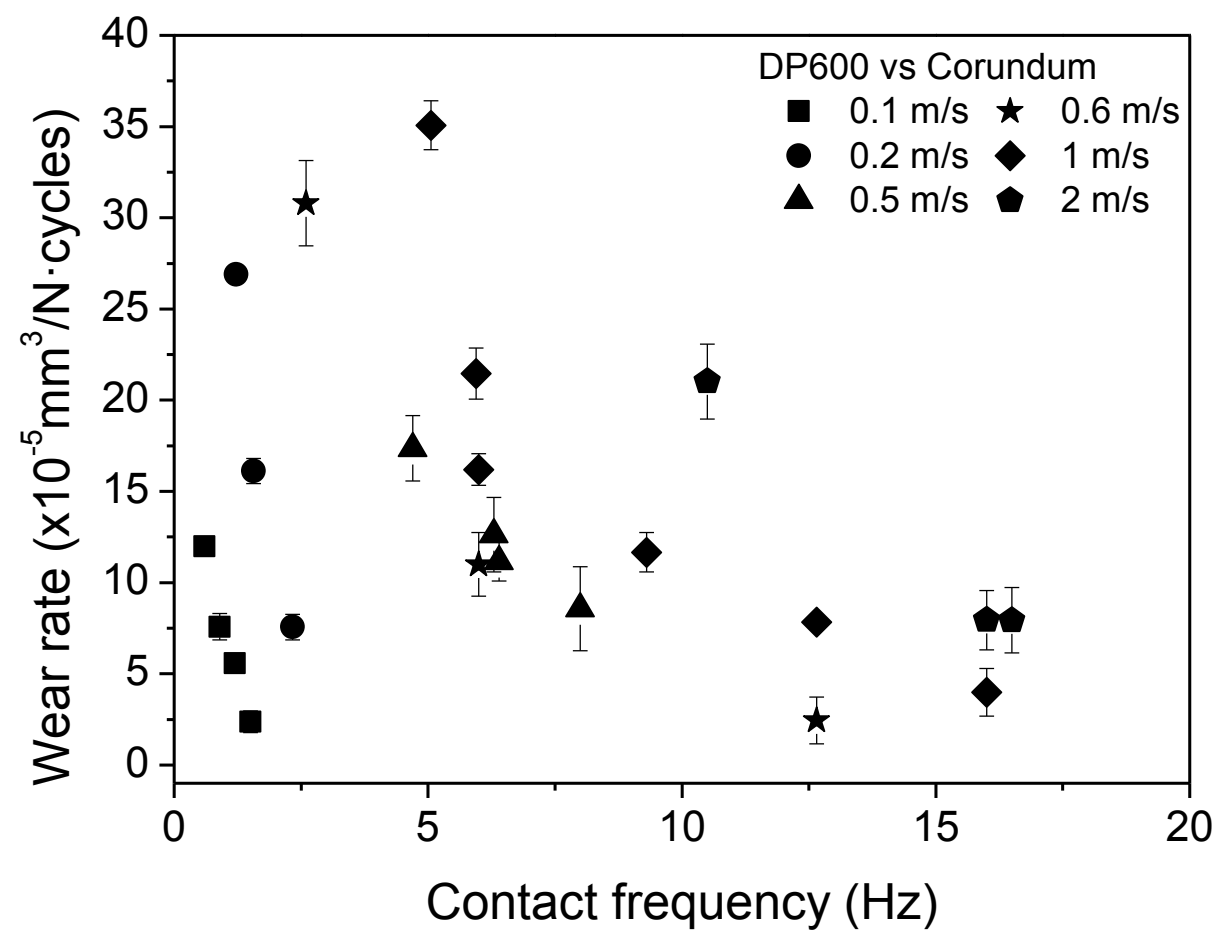


Figure 14

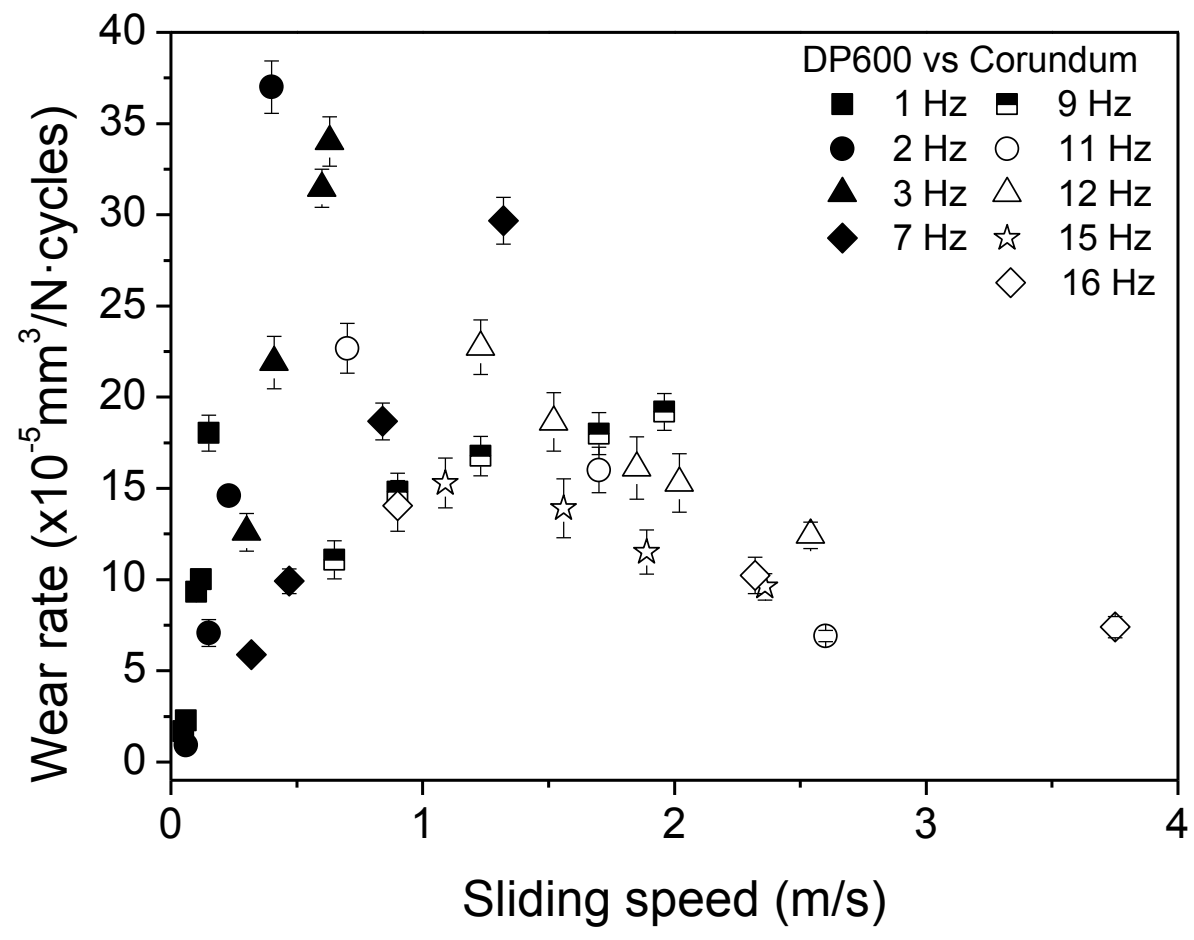


Figure 15

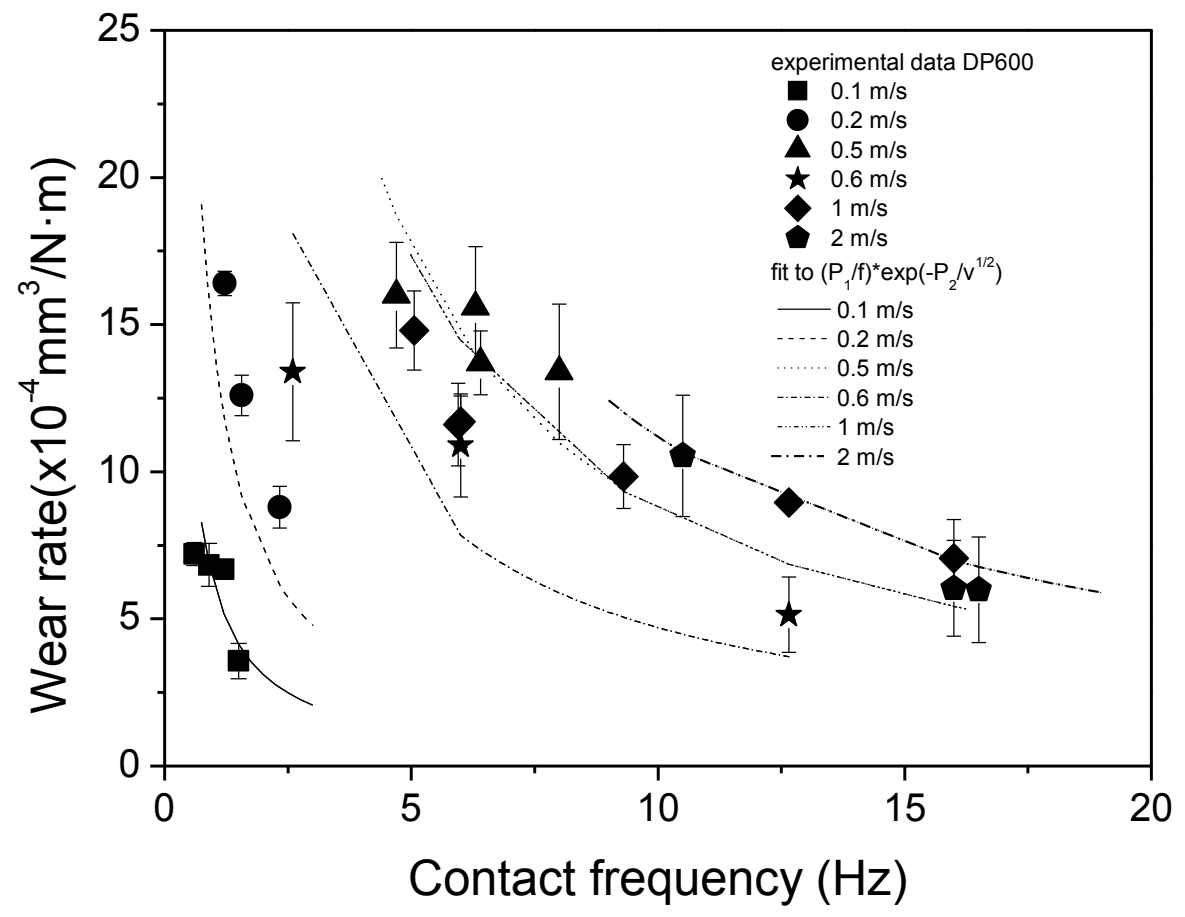


Figure 16
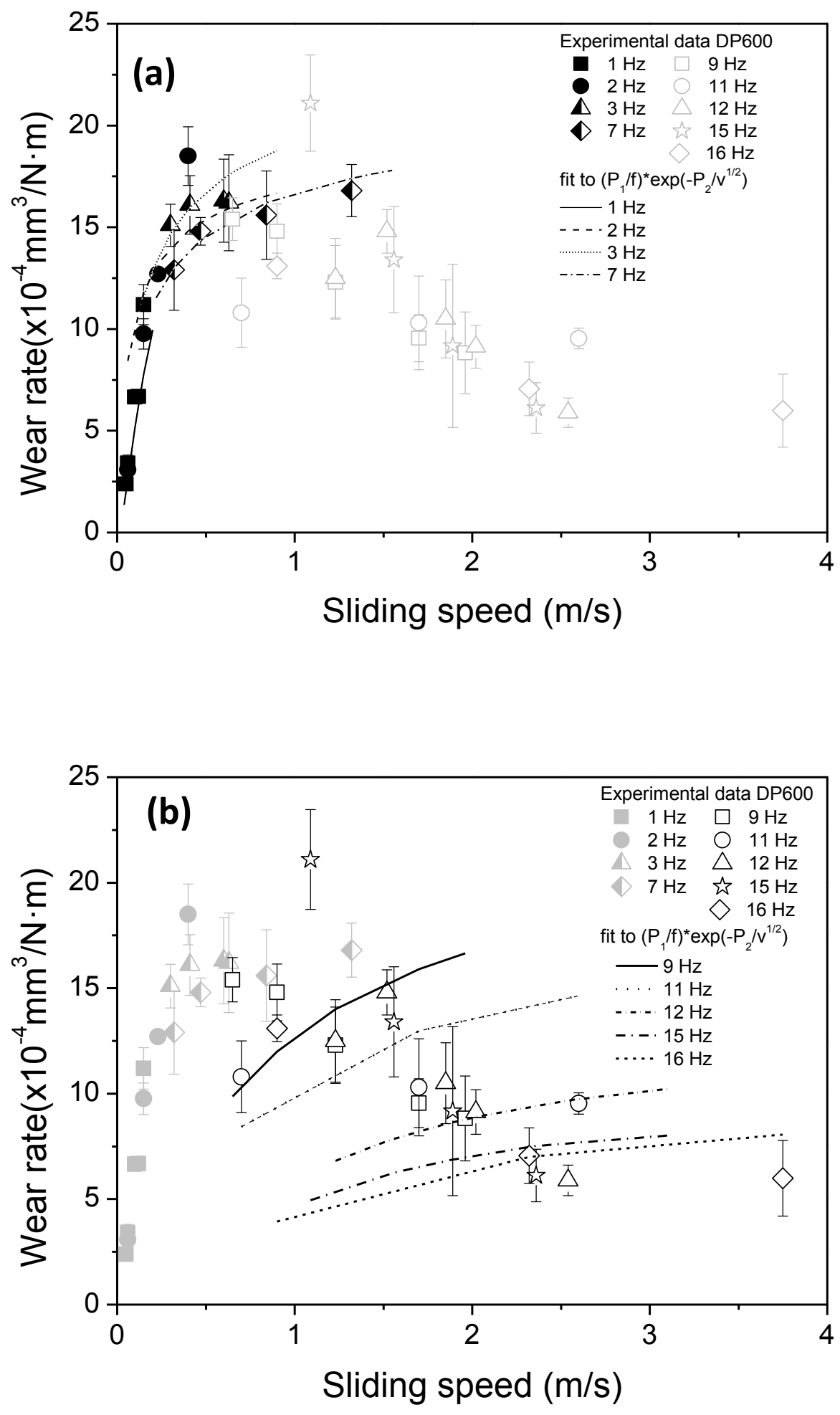
Figure 17

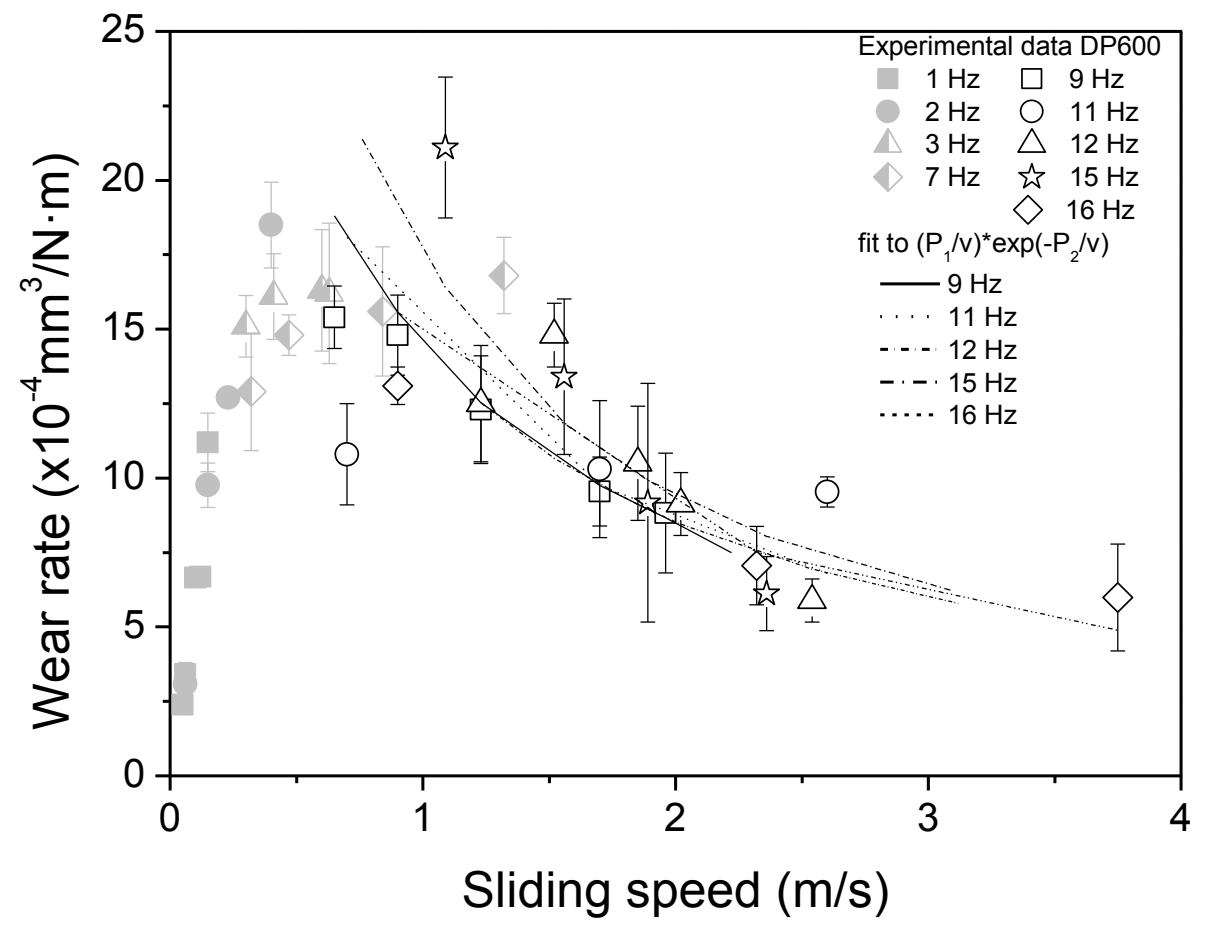


Table 1

$\begin{array}{llllllllll}\mathrm{C} & \mathrm{Si} & \mathrm{Mn} & \mathrm{Cr} & \mathrm{Ni} & \mathrm{Mo} & \mathrm{Al} & \mathrm{Nb} & \mathrm{V} & \mathrm{Fe}\end{array}$

\begin{tabular}{lllllllllll}
\hline DP600 & 0.122 & 0.38 & 0.91 & 0.021 & 0.045 & $<0.01$ & 0.043 & $<0.005$ & $<0.01$ & Balanced
\end{tabular}

